\title{
Differential expression of liver proteins between obesity-prone and obesity-resistant rats in response to a high-fat diet
}

\author{
Xia Wang, Jung-Won Choi, Jeong In Joo, Dong Hyun Kim, Tae Seok Oh, Duk Kwon Choi \\ and Jong Won Yun* \\ Department of Biotechnology, Daegu University, Kyungsan, Kyungbuk 712-714, Republic of Korea
}

(Received 2 September 2010 - Revised 1 December 2010 - Accepted 18 January 2011 - First published online 3 May 2011)

\begin{abstract}
Rodents respond to a chronic high-fat diet (HFD) in two ways: some readily become obese (obesity prone, OP) and others do not (obesity resistant, OR). Although several hypotheses have been proposed, the mechanisms underlying the inter-individual susceptibility to dietinduced obesity remain to be fully defined. In the present study, two-dimensional gel electrophoresis (2-DE) combined with matrixassisted laser desorption ionisation time-of-flight MS was carried out for identification of differentially expressed liver proteins in OP and OR rats fed a HFD, in an attempt to discover marker proteins involved in susceptibility and/or resistance to obesity in rat liver. The 2-DE analysis demonstrated that forty spots from 380 visualised spots were differentially regulated between the groups. Among these forty spots, twelve were differentially expressed proteins between OP and OR rats, reaching statistical significance. Of these, five proteins have already been linked to obesity; however, seven proteins involved in obesity susceptibility or resistance were identified for the first time in the present study. In order to validate the proteomic results and gain insight into the metabolic changes between the OP and OR groups, we further confirmed the expression pattern of some proteins of interest by Western blot analysis. Combined results of proteomic analysis with Western blot analysis revealed that reduced lipogenesis and increased fat oxidation were achieved in the livers of OR rats. In conclusion, the present proteomic study is an important advance over the previous steps required for identification of OP and OR rats, and should prove valuable in the search for the pathogenesis of obesity in humans.
\end{abstract}

\section{Key words: Two-dimensional gel electrophoresis: High-fat diet: Liver proteomics: Obesity-prone/resistant rats}

Obesity has become the most common metabolic and nutritional disorder in developed countries, and represents one of the most prevalent risk factors for the development of common chronic metabolic diseases, such as atherosclerosis and diabetes $^{(1)}$. One of the major issues in the field of obesity research is the question of why some humans easily become obese (obesity prone, OP) and others resist the development of obesity (obesity resistant, OR) when exposed to highenergy diets. Once exposed to a high-energy diet, OR and OP subjects differ markedly in their regulation of food intake and metabolic efficiency. Although several hypotheses have been proposed, the mechanisms underlying interindividual susceptibility to diet-induced obesity (DIO) remain to be fully defined. A large number of factors including physiological signalling and responsiveness, metabolic processes, and genetic differences have been associated with susceptibility to obesity ${ }^{(2,3)}$.
Different strains of rats are known to differ in their susceptibility to dietary obesity ${ }^{(2)}$. The model of DIO in Sprague-Dawley rats is of special interest with regard to the regulation of energy homeostasis. When fed a diet moderately high in fat, about half of the rats develop DIO, whereas the rest are diet resistant ${ }^{(2)}$. In the search for an explanation for the differing propensities for obesity susceptibility in rats fed a high-fat diet (HFD), blood and several tissues, such as hypothalamus, adipose tissues and skeletal muscle, have been targeted in rodent models in this laboratory.

Compared with OR rats, OP rats have several deficits in central nervous system function. Levin \& Sullivan ${ }^{(4)}$ pointed out that glucose-induced noradrenaline (NA) levels are closely associated with obesity resistance. They have found that plasma NA levels after a glucose load in OR rats were lower than those in OP rats, providing a positive correlation between NA levels and subsequent weight gain. OP rats have a

\footnotetext{
Abbreviations: A1AT, $\alpha 1$-anti-trypsin; ACC, acetyl-CoA carboxylase; ACN, acetonitrile; ACSM1, acyl-CoA synthetase medium-chain family member 1; AMPK, adenosine monophosphate-activated protein kinase; ASS1, argininosuccinate synthetase 1; AST, aryl sulfotransferase; BCS1, butyryl coenzyme A synthetase 1; CES3, carboxylesterase 3; CPT, carnitine palmitoyltransferase; DIO, diet-induced obesity; Es22, esterase 22; ESD, esterase D; EH, epoxide hydrolases; FAS, fatty acid synthase; GP, glycogen phosphorylase; HFD, high-fat diet; HSP, heat shock proteins; IEF, isoelectric focusing; LFD, low-fat diet; $\mathrm{MDH}$, malate dehydrogenase; NA, noradrenaline; OCT, ornithine carbamoyltransferase; OP, obesity prone; OR, obesity resistant; TBS-T, Tris-buffered saline containing $0 \cdot 1 \%$ Tween-20; UCP2, uncoupling protein 2.
}

*Corresponding author: Dr J. W. Yun, fax +82 538506559 , email jwyun@daegu.ac.kr 
diminished rate of NA clearance from the plasma, whereas OR rats require less sympathetic activation because of their increased sensitivity to NA. These results suggest that the balance between pre- and post-synaptic NA actions appears to be a critical factor in the differentiation of $O P$ from $O R$ rats, and may be important in their body-weight gain patterns on $\mathrm{HFD}^{(5-8)}$. It has also been demonstrated that $\mathrm{OR}$ rats have a greater glucose-induced stimulation of their sympathetic nervous system than $\mathrm{OP}$ rats. Taken together, glucose and insulin metabolism and their interface with the sympathetic nervous system appear to be important determining factors with regard to which animals might be predisposed to resist the development of $\mathrm{DIO}^{(4)}$.

Involvement of enhanced fat oxidation and oxidative capacity in skeletal muscle in resistance to DIO has been reported. Increased fat metabolism in muscle may contribute to the obesity resistance of rodents, enabling circulating lipids elevated by diet to be oxidised in the muscle rather than deposited in the adipose tissue ${ }^{(9,10)}$. A relationship has been supposed between the composition of skeletal muscle and susceptibility or resistance to HFD-induced obesity ${ }^{(9)}$. It has been demonstrated that an average daily respiratory quotient in OR rats was significantly lower than that in OP rats, suggesting a greater daily oxidation of fat in OR rats ${ }^{(9)}$. A greater proportion of type I fibres has been reported to be associated with a greater capacity for fat oxidation, which would favour resistance to body fat accumulation ${ }^{(10)}$.

Adipocytes from OP mice have greater sensitivity to insulin compared with those from OR mice because OP mice take up more glucose than OR mice, thereby increasing lipogenesis $^{(11)}$. Defective oxygen consumption in brown adipose tissue also affects obesity development. Brown adipose tissue of obese rats has a diminished respiratory rate compared with that of lean rats due to the inability of the mitochondria to utilise NEFA for the production of enhanced oxygen consumption $^{(12)}$. Recently, the liver has been targeted by many investigators to unravel the metabolic differences between $\mathrm{OP}$ and $\mathrm{OR}$ rats because it plays a pivotal role in lipid homeostatic response to feeding conditions ${ }^{(13-16)}$. In the present study, we hypothesised that differential expression of proteins in the liver is likely to contribute to this response. We thus performed proteomic analysis on liver proteins to assess which metabolic changes cause OP and OR propensity in rats fed a HFD.

Numerous proteomic studies in the liver of human subjects and rodents have been reported in order to provide a liver proteome dataset ${ }^{(17,18)}$ and to find liver toxicity markers ${ }^{(19)}$. Also, in order to provide a strong basis for the investigation of liver pathobiology and for a better understanding, diagnosis and prevention of hepatic diseases, many improved methods for liver proteomic analysis have been demonstrated ${ }^{(20-26)}$. However, a proteomic study to profile the differential expression of liver proteins in an attempt to distinguish the phenotypic difference between OP and OR has not yet been performed.

The goals of the present study were (1) to achieve a detailed understanding of molecular changes in response to HFD feeding in rat liver and (2) to find hepatic marker proteins determining the metabolic differences between OP and
OR rats through identification of differentially expressed proteins in rat liver.

\section{Materials and methods}

\section{Animals and breeding conditions}

Male Sprague-Dawley rats, 5 weeks old, were purchased from Japan SLC (Hamamatsu, Japan) and were maintained in the animal facility at the Department of Biotechnology, Daegu University (Gyeongsan, South Korea). All rats were provided water and standard chow ad libitum for 1 week before the start of any experimental procedures in order to allow them to acclimatise to their new surroundings. Rats were raised in separate cages in order to exclude diverse effects among them. They were randomly divided into two groups: eight rats fed a low-fat diet (LFD, 12\% energy from fat) and thirty-seven rats fed on a HFD ( $45 \%$ energy from fat). These feeds were purchased from Feed Korea Lab (Hanam, Kyungki, Republic of Korea), and the dietary composition of the LFD and HFD is shown in Table 1. The weights of the rats were recorded every alternative day for $56 \mathrm{~d}$, and the HFD-fed rats were subdivided into OP $(n 6)$ and OR rats $(n 6)$ according to the highest and lowest body-weight gain, respectively. Rats were deprived of food for at least $12 \mathrm{~h}$ before killing, and they were anaesthetised with 3\% diethyl ether. These experiments were approved by the Committee for Laboratory Animal Care and Use of Daegu University. All procedures were conducted in accordance with the Guide for the Care and Use of Laboratory Animals published by the National Institutes of Health.

\section{Plasma biochemical parameters}

Blood samples were obtained by resection at the end of the rat tail under anaesthesia, and plasma was separated by

Table 1. Dietary composition of the experimental diets

\begin{tabular}{lrc}
\hline & LFD & HFD \\
\hline Composition by weight (g/kg) & & \\
Casein & 200 & 200 \\
Maize starch & 150 & 155 \\
Sucrose & 500 & 50 \\
Dextrose & 0 & 132 \\
Cellulose & 50 & 50 \\
Soyabean oil & 0 & 25 \\
Maize oil & 50 & 0 \\
Lard & 0 & 175 \\
Mineral mix & 35 & 35 \\
Vitamin mix & 10 & 10 \\
TBHQ & 0 & 0.014 \\
L-Cystine & 0 & 3 \\
DL-Methionine & 3 & 0 \\
Choline bitartrate & 2 & $2 \cdot 5$ \\
Composition by energy (\%) & & \\
Protein & 21 & 20 \\
Carbohydrate & 68 & 35 \\
Fat & 12 & 45 \\
Total & $16326 \mathrm{~kJ}$ & $19983 \mathrm{~kJ}$ \\
\hline
\end{tabular}

LFD, low-fat diet; HFD, high-fat diet; TBHQ, tertiary butylhydroquinone. 
centrifugation $(3000 \boldsymbol{g}, 10 \mathrm{~min})$. Total cholesterol and HDLcholesterol in plasma were enzymatically measured using commercial kits of Bio Clinical System Corporation (Anyang, Kyungki, Republic of Korea), and TAG and glucose were determined using enzymatic kits (Asan Phamaceutical, Seoul, Republic of Korea). NEFA were quantified using an enzymatic fatty acid quantification kit (Abcam, Cambridge, UK). They were measured according to the manufacturer's instructions.

\section{Hepatic lipid contents}

Hepatic lipids were extracted using the procedure developed by Folch et $a l .{ }^{(27)}$. Briefly, $0 \cdot 1 \mathrm{~g}$ liver samples were homogenised in $2 \mathrm{ml}$ of $20 \mathrm{~mm}$-potassium phosphate buffer. After adding $5 \mathrm{ml}$ of chloroform and methanol (1:1) solution, the samples were incubated at $25^{\circ} \mathrm{C}$ for $1 \mathrm{~h}$. Then, $2.5 \mathrm{ml}$ of chloroform solution and $0.8 \mathrm{ml}$ of $0.74 \%$ potassium chloride solution were added to all the samples. The samples were centrifuged at $2000 \mathrm{~g}$ for $5 \mathrm{~min}$. The resulting precipitates were transferred to new tubes, to which $0.72 \mathrm{ml}$ of $0.74 \%$ potassium chloride solution, $0.735 \mathrm{ml}$ chloroform and $0.46 \mathrm{ml}$ methanol were added. Mixed samples were dried under $\mathrm{N}_{2}$, and the dried lipid residues were dissolved in $1 \mathrm{ml}$ ethanol for total cholesterol and TAG measurements. Triton X-100 and a sodium cholate solution were added to $0.2 \mathrm{ml}$ of the dissolved lipid solution to produce final concentrations of $5 \mathrm{~g} / \mathrm{l}$ and $3 \mathrm{mmol} / \mathrm{l}$, respectively. Total cholesterol and TAG levels were determined using enzymatic kits (Asan Phamaceutical), according to the manufacturer's instructions.

\section{Hepatic lipid metabolic enzyme activity}

Fatty acid synthase (FAS) activity was measured in accordance with the method described by Nepokroeff et $a l{ }^{(28)}$ by monitoring the malonyl-CoA-dependent oxidation of NADPH at $340 \mathrm{~nm}$, where the activity is expressed as the oxidised $\mathrm{NADPH} \mathrm{nmol} / \mathrm{min}$ per $\mathrm{mg}$ protein. Malic enzyme activity was determined according to the process of Ochoa ${ }^{(29)}$ by viewing the production of NADPH at $340 \mathrm{~nm}$, and the activity is expressed as the formation of $\mathrm{NADPH} \mathrm{nmol} / \mathrm{min}$ per $\mathrm{mg}$ protein. $\beta$-Oxidation activity was determined using the method of Lazarow ${ }^{(30)}$ by monitoring the reduction of NAD to NADH at $340 \mathrm{~nm}$, where the activity is expressed as the reduced $\mathrm{NAD} \mathrm{nmol} / \mathrm{min}$ per $\mathrm{mg}$ protein. Carnitine palmitoyltransferase (CPT) activity was determined according to the method described by Markwell et al. ${ }^{(31)}$. The results are expressed as $\mathrm{nmol} / \mathrm{min}$ per mg protein. Protein content was determined according to the method used by Bradford ${ }^{(32)}$ using bovine serum albumin as the standard.

\section{Preparation of liver samples for two-dimensional gel electrophoresis}

Liver tissues of the rats were isolated immediately after killing and then washed with a cold $\mathrm{NaCl}$ solution. The liver tissues were pulverised under liquid $\mathrm{N}_{2}$ and stored at $-80^{\circ} \mathrm{C}$ until use. The tissues were lysed in $0.3 \mathrm{ml}$ rehydration buffer solution containing $7 \mathrm{M}$-urea, $2 \mathrm{M}$-thiourea, $4 \%$ 3-((3-cholamidopropyl)dimethylammonio)-1-propane sulfonic acid, $20 \mathrm{~mm}$-dithiothreitol, $1 \mathrm{~mm}$-phenylmethanesulfonyl fluoride, $2 \%$ IPG (immobilised $\mathrm{pH}$ gradients) buffer and a trace of bromophenol blue. Tissues were homogenised on ice using a homogeniser (PT 1200E; Kinematica Limited, Luzern, Switzerland). The homogenates were centrifuged at $14000 \mathrm{~g}$ for $20 \mathrm{~min}$; the supernatant was then stored at $-80^{\circ} \mathrm{C}$ until analysis. Protein content of the liver tissue was determined by the Bradford method ${ }^{(32)}$ using Bradford reagent (SigmaAldrich, St Louis, MO, USA).

\section{Two-dimensional gel electrophoresis}

IPG drystrips (18 cm, pH 3-10; Amersham Biosciences, Little Chalfont, Buckingham, UK) were used for isoelectric focusing (IEF); $150 \mu \mathrm{g}$ of protein were adjusted to a volume of $0.35 \mathrm{ml}$ with rehydration buffer solution, and the IPG drystrips were rehydrated overnight in a stripholder. IEF was then performed using the PROTEIN IEF cell (Bio-Rad, Hercules, CA, USA) according to the protocol suggested by the manufacturer. Following IEF, the strips were equilibrated in solution A, containing $6 \mathrm{~m}$-urea, 2\% SDS, 30\% glycerol, 1\% dithiothreitol and $50 \mathrm{~mm}-$ Tris ( $\mathrm{pH} \mathrm{8.8)} \mathrm{for} 15 \mathrm{~min}$, and then in solution $\mathrm{B}$, same as A, replacing dithiothreitol with $2.5 \%$ iodoacetamide, for an additional $15 \mathrm{~min}$. Equilibrated IPG strips were then rinsed with electrophoresis buffer. The strips were placed on an $8 \%(\mathrm{w} / \mathrm{v})$ $20 \times 20 \mathrm{~cm}$ SDS-polyacrylamide gel for resolution in the second dimension. Thereafter, two-dimensional gel electrophoresis was performed at a constant voltage of $15 \mathrm{~mA}$ per gel for $16 \mathrm{~h}$; separated gels were then visualised using Ag staining ${ }^{(33,34)}$.

\section{Image acquisition}

Gels were scanned on a UMAX PowerLook 1120 (Maxium Technologies, Inc., Taipei, Taiwan), and the resulting images were converted to the tagged image file format before analysis. Intensity calibration was performed using an intensity step wedge before the gel image. Comparison of images was performed using a modified version of ImageMaster 2D software version 4.95 (Amersham Biosciences). A reference gel was selected at random from gels of the control group for each experiment, and spots detected from other gels in the control dataset were matched with those in the selected reference gel. Relative optical density and relative volume were also calculated in order to correct for differences in gel staining. Each spot intensity volume was processed by background subtraction and total spot volume normalisation; the resulting spot volume percentage was used for comparison ${ }^{(33)}$.

\section{Enzymatic digestion of protein in gel}

Using modified porcine trypsin, protein spots were enzymatically digested in gel in a manner similar to that described previously by Shevchenko et al. ${ }^{(35)}$. Gel pieces were washed with $50 \%$ acetonitrile (ACN) to remove SDS, salts and stains. The gel was then dried in order to remove the solvent, rehydrated with trypsin $(8-10 \mathrm{ng} / \mathrm{ml})$ and incubated for $8-10 \mathrm{~h}$ at $37^{\circ} \mathrm{C}$. The proteolytic reaction was terminated by the addition 
of $5 \mathrm{ml}$ of $0.5 \%$ trifluoroacetic acid. Tryptic peptides were recovered by combining the aqueous phase from repeated extraction of gel pieces with $50 \%$ ACN. After concentration, the peptide mixture was redissolved in the buffer and desalted using C18ZipTips (Millipore, Watford, Herts, UK), and peptides were eluted with $1-5 \mathrm{ml}$ of $\mathrm{ACN}$. An aliquot of this solution was mixed with an equal volume of a saturated solution of $\alpha$-cyano-4-hydroxycinnamic acid in $50 \% \mathrm{ACN}$, and $1 \mu \mathrm{l}$ of the mixture was spotted onto a target plate ${ }^{(33,34)}$.

\section{Protein identification}

For protein identification by peptide mass fingerprinting, protein spots were excised, digested with trypsin (Promega, Madison, WI, USA), mixed with $\alpha$-cyano-4-hydroxycinnamic acid in $50 \%$ ACN-0.1\% trifluoroacetic acid and subjected to matrix-assisted laser desorption/ionisation time-of-flight analysis (Ettan MALDI-TOF Pro; Amersham Biosciences, Piscataway, NJ, USA), as described by Fernandez et al. ${ }^{(36)}$. Spectra were collected from 350 shots per spectrum over the $m / z$ range $600-3000$ and calibrated by two-point internal calibration using trypsin autodigestion peaks $(\mathrm{m} / z 842.5099$ and 2211-1046). Peak list was generated using the Ettan MALDI-TOF Pro Evaluation Module (version 2.0.16). Threshold used for peak-picking was as follows: 5000 for minimum resolution of monoisotopic mass, 2.5 for signal: noise ratio. The search program MASCOT, developed by Matrix Science (London, UK; http://www.matrixscience. com), was used for protein identification by peptide mass fingerprinting. The following parameters were used for database search: trypsin as the cleaving enzyme; a maximum of one missed cleavage; iodoacetamide (cystine) as a complete modification; oxidation (methionine) as a partial modification; monoisotopic masses; a mass tolerance of $\pm 0 \cdot 1 \mathrm{Da}$. MASCOT probability-based molecular-weight-search score was calculated for peptide mass fingerprinting. Protein score is $-10 \times \log (P)$, where $P$ is the probability that the observed match is a random event, and protein scores $>61$ are considered significant $(P<0 \cdot 05)^{(33,34)}$.

\section{Immunoblot analysis}

Tissue lysates were prepared with radioimmunoprecipitation assay buffer (Sigma-Aldrich), homogenised and centrifuged at $12000 \mathrm{~g}$ for $20 \mathrm{~min}$. The extract was diluted in sample buffer (50 mm-Tris, pH 6.8, 2\% SDS, $10 \%$ glycerol, $0 \cdot 1 \%$ bromophenol blue and $5 \% \beta$-mercaptoethanol) and heated for $5 \mathrm{~min}$ in a boiling bath. Samples were then subjected to SDS-polyacrylamide gel for electrophoresis and transferred to PolyScreen membranes (NEN, Boston, MA, USA). The membranes were subsequently blocked with 5\% non-fat dry milk in Tris-buffered saline (10 mm-Tris- $\mathrm{HCl}, 150 \mathrm{~mm}-\mathrm{NaCl}, \mathrm{pH}$ 7.5) containing 0.1\% Tween-20 (TBS-T). After washing with TBS-T, the membranes were probed with a primary antibody. The following antibodies were used in the present study: antirabbit adenosine monophosphate-activated protein kinase (AMPK); p-AMPK; acetyl-CoA carboxylase (ACC); p-ACC; FAS; CPT1 (Santa Cruz Biotechnology, Santa Cruz, CA, USA); anti-goat CES3; argininosuccinate synthetase 1 (ASS1); MDH (Santa Cruz Biotechnology); anti-mouse $\beta$-actin (Santa Cruz Biotechnology). After washing with TBS-T, the membranes were incubated for $2 \mathrm{~h}$ with horseradish peroxidaseconjugated anti-rabbit IgG, anti-goat IgG and anti-mouse IgG secondary antibody (1:1000; Santa Cruz Biotechnology), and was developed using enhanced chemiluminescence (Intron, Seoul, Republic of Korea). Western blot was analysed by scanning with a UMAX PowerLook 1120 (Maxium Technologies, Akron, OH, USA) and digitalisation using image analysis software (KODAK 1D, Eastman Kodak, Rochester, NY, USA).

\section{Statistical analysis}

All experimental results were compared by one-way ANOVA using the Statistical Package of Social Science (version 14.0K; SPSS, Chicago, IL, USA) program. Data are expressed as means with their standard errors. Group means were considered significant at $P<0 \cdot 05$, as determined by the technique of protected least-significant difference when ANOVA indicated an overall significant treatment effect $(P<0 \cdot 05)^{(34)}$.

\section{Results}

High-fat diet-induced obesity-prone and obesity-resistant phenotypes

Rats were randomly divided into two groups, with eight rats fed a LFD as the control group and thirty-seven rats fed a HFD, and the latter was subdivided into OP $(n$ 6) and OR rats $(n 6)$ according to their body-weight gain. Changes in body weight between the groups during the experimental period are shown in Fig. 1(a). Body weights of the rats were much the same at the beginning of the present study; however, they began to diverge after 4 weeks, such that OP rats were heavier $(P<0.01)$ than the normal controls and OR rats at all subsequent time points. Consequently, the total body weight of OP rats was higher by an average of approximately $25 \%$ compared with OR rats (Fig. 1(b)). The concentration of plasma HDL-cholesterol was significantly lower in OP rats compared with that of OR rats, whereas TAG, glucose and NEFA levels were remarkably higher in OP rats than those in normal and OR rats (Table 2). Hepatic lipid levels showed a tendency to be higher in OP rats compared with normal and OR rats, and they were higher in OR rats than in normal rats (Table 2). In addition, activities of hepatic lipid metabolic enzymes were investigated in each group. Consequently, while CPT activity was significantly lower in OP rats compared with normal and OR rats, FAS, malic enzyme and $\beta$-oxidation activities were slightly higher in OP rats compared with those in OR rats, even though they did not reach statistical significance (Table 3).

\section{Analysis of two-dimensional gel electrophoresis images of rat liver proteome}

Liver proteins isolated from the most representative nine rats in the normal ( $n$ 3), OP ( $n$ 3) and OR groups ( $n$ 3) were individually arrayed using two-dimensional gel electrophoresis. 

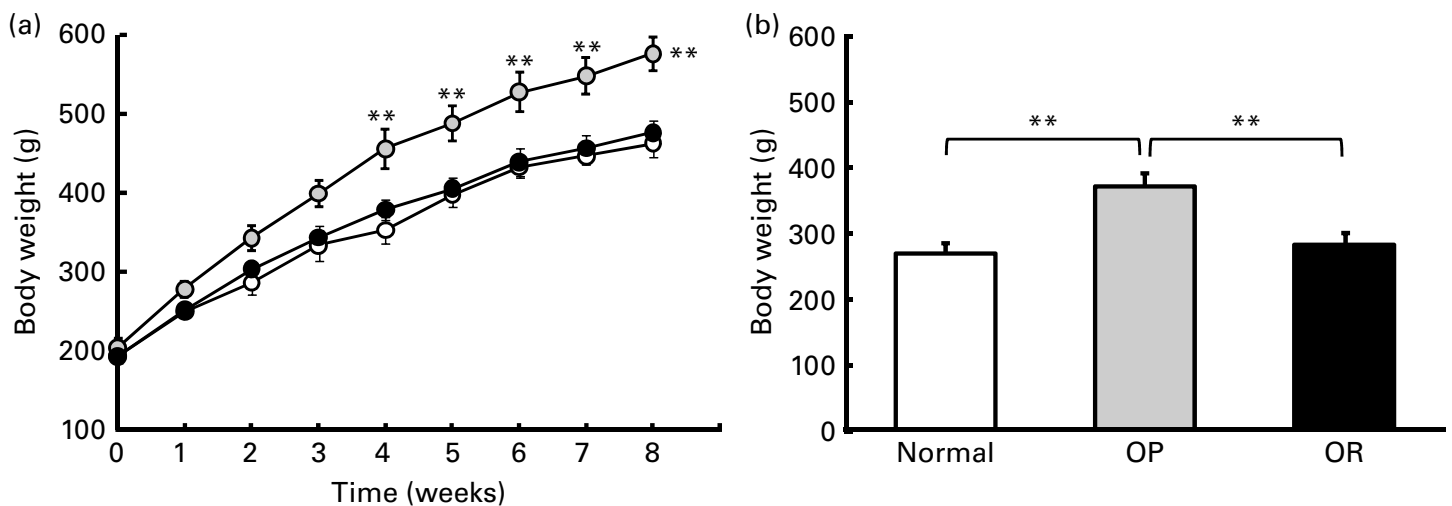

Fig. 1. High-fat diet (HFD)-induced obesity-prone (OP) and obesity-resistant (OR) phenotypes. (a) Body-weight profiles of normal rats fed a standard diet (low-fat diet) $\left(-\mathrm{O}^{-}\right.$) and OP (-O-) and OR (- - ) rats fed a HFD. (b) Total body-weight gain of normal, OP and OR rats (six animals per group). Values are means (six animals per group), with their standard errors represented by vertical bars (estimated using the ANOVA test). Mean values were significantly different between each group: ${ }^{*} P<0.01$

In order to obtain more accurate results, two-dimensional gel electrophoresis analysis was performed twice on the proteins of each group; thus, a total of eighteen gels were used. Liver proteins were separated using IEF on an IPG strip ( $\mathrm{pH} \mathrm{3-10)}$ for the first dimension and 8\%(w/v) SDS-PAGE gel for the second dimension. As a result, expression levels of approximately 400 spots were detected, ranging from 20 to $240 \mathrm{kDa}$ mass between pH 3 and 10 (Fig. 2). Positions of all identified proteins on two-dimensional gel electrophoresis gels were in the expected range of their theoretical $\mathrm{p} I$ and molecular weights (Table 4). It was found that a total of eleven proteins were up-regulated, whereas seventeen proteins were downregulated upon HFD feeding.

\section{Changes in liver protein levels between obesity-prone and obesity-resistant rats}

Image analysis and further statistical analysis allowed detection and identification of forty proteins whose differences showed prominence between the normal group and the HFD-fed groups (OP and OR). Among the forty differentially expressed spots, twelve proteins were significantly changed upon HFD feeding between the OP and OR groups: five proteins including esterase 22 (Es22) precursor (-3.14-fold, $P=0.0002)$, ASS1 ( -1.83 -fold, $P=0.0007), \alpha 1$-anti-trypsin (A1AT) precursor $(-2 \cdot 58$-fold, $P=0.0002)$, epoxide hydrolase 2 (EH2), cytoplasmic, isoform CRA-b ( $-3 \cdot 37$-fold, $P=0.0002)$ and malate dehydrogenase $(\mathrm{MDH})$, cytoplasmic ( $-1 \cdot 68$-fold, $P=0.0006)$ were decreased, whereas seven proteins including glycogen phosphorylase (GP), liver form (2.21-fold, $P=0.0003$ ), carboxylesterase 3 (CES3; 1.96-fold, $P=0.07 \times 10^{-3}$ ), aryl sulfotransferase (AST; 1.46-fold, $P=0.003$ ), ornithine carbamoyltransferase (OCT) precursor (2.1-fold, $P=0 \cdot 0002)$, butyryl coenzyme A synthetase 1 (BCS1; 2.08-fold, $P=0 \cdot 0003$ ), heat shock cognate $71 \mathrm{kDa}$ protein (heat shock protein 70 (HSP70); 1.76-fold, $P=0.0003)$ and esterase D (ESD)/formylglutathione hydrolase (1.37-fold, $P=0.003$ ) were increased in OP rats compared with normal and OR rats (Figs. 3 and 4; Table 4).

\section{Validation of proteomic data using Western blot analysis}

Although the present proteomic data indicated differential expression of proteins among the experimental groups, we could not exclude the possibility of technical errors and artificial effects in proteomic analysis. To address this issue, the expression patterns of some potential marker proteins,

Table 2. Plasma biochemical parameters and hepatic lipid profiles in normal, obesity-prone (OP) and obesity-resistant (OR) rats

(Mean values with their standard errors of three separate experiments)

\begin{tabular}{|c|c|c|c|c|c|c|}
\hline & \multicolumn{2}{|c|}{ Normal } & \multicolumn{2}{|c|}{ OP } & \multicolumn{2}{|c|}{ OR } \\
\hline & Mean & SEM & Mean & SEM & Mean & SEM \\
\hline \multicolumn{7}{|l|}{ Plasma } \\
\hline Total cholesterol (mg/ml) & 0.3 & $0 \cdot 14$ & 0.66 & $0 \cdot 18$ & 0.24 & 0.01 \\
\hline HDL-cholesterol (mg/ml) & 0.57 & 0.02 & $0.24^{b}$ & 0.06 & 0.58 & 0.07 \\
\hline TAG (mg/ml) & $0.39^{a}$ & 0.07 & $1.01^{\mathrm{b}}$ & 0.04 & 0.43 & 0.02 \\
\hline Glucose $(\mathrm{mg} / \mathrm{ml})$ & $2 \cdot 06^{a}$ & 0.1 & $2 \cdot 69^{b}$ & 0.04 & $1 \cdot 7$ & 0.14 \\
\hline NEFA $(\mu \mathrm{mol} / \mathrm{ml})$ & 1.7 & 0.23 & $2 \cdot 06^{\mathrm{b}}$ & 0.03 & 1.7 & 0.04 \\
\hline \multicolumn{7}{|l|}{ Liver } \\
\hline Total cholesterol (ng/g) & 4.86 & 0.26 & $8 \cdot 41$ & $2 \cdot 13$ & $6 \cdot 55^{\mathrm{c}}$ & 0.13 \\
\hline TAG (ng/g) & $11.52^{\mathrm{a}}$ & 0.2 & $17 \cdot 06$ & 0.78 & $14 \cdot 73^{c}$ & 0.02 \\
\hline
\end{tabular}


Table 3. Hepatic lipid metabolic enzyme activity in normal, obesity-prone $(\mathrm{OP})$ and obesity-resistant $(\mathrm{OR})$ rats

(Mean values with their standard errors of three separate experiments)

\begin{tabular}{|c|c|c|c|c|c|c|}
\hline & \multicolumn{2}{|c|}{ Normal } & \multicolumn{2}{|c|}{ OP } & \multicolumn{2}{|c|}{ OR } \\
\hline & Mean & SEM & Mean & SEM & Mean & SEM \\
\hline \multicolumn{7}{|c|}{ Fatty acid synthesis (nmol/min per mg protein) } \\
\hline FAS & 0.07 & 0.02 & 0.13 & 0.03 & 0.08 & 0.03 \\
\hline ME & 0.04 & 0.02 & 0.05 & 0.01 & 0.03 & 0.00 \\
\hline \multicolumn{7}{|c|}{ Fatty acid oxidation (nmol/min per mg protein) } \\
\hline$\beta$-Oxidation & 0.05 & 0.01 & 0.04 & 0.01 & 0.03 & 0.00 \\
\hline CPT & $0.14^{a}$ & 0.01 & $0.12^{\mathrm{b}}$ & 0.00 & 0.16 & 0.01 \\
\hline
\end{tabular}

FAS, fatty acid synthase; ME, malic enzyme; CPT, carnitine palmitoyltransferase.

${ }^{\mathrm{a}, \mathrm{b}}$ Mean values with unlike superscript letters were significantly different between each group $(P<0.05)$.

including CES3, MDH and ASS1, were further confirmed by immunoblot analysis. As shown in Fig. 5(a), expression levels of all tested proteins were firmly consistent with those of the proteomic study.

\section{Differential expression of lipogenic- and $\beta$-oxidation-related proteins between obesity-prone and obesity-resistant rats by Western blot analysis}

We also examined differential expression patterns for some lipogenic- and $\beta$-oxidation-related proteins in the liver of each group, which could not be detected by proteomic analysis (Fig. 5(b)). FAS and ACC (active form p-ACC) were markedly decreased in OR rats, whereas AMPK (active form p-AMPK) was highly activated in OR rats, suggesting that fatty acid synthesis was obviously suppressed in the liver tissues of OR rats. CPT1, which is a rate-limiting enzyme in $\beta$-oxidation of fatty acid, was highly expressed in the OR rats compared with $\mathrm{OP}$ and normal rats. Unexpectedly, levels of uncoupling protein 2 (UCP2), as a negative regulator of reactive oxygen species production, in OP rats were higher than those in OR rats.

\section{Discussion}

In the present study, to address the question of which metabolic changes cause reduced adiposity and resistance to obesity in HFD-fed rats, the effect of the HFD on the expression of proteins in rat liver was analysed using a proteomic approach. Although several hypotheses have been proposed so far, the mechanisms underlying inter-individual susceptibility to DIO remain unclear. We therefore employed a proteomic approach for the examination of global protein expression change in the liver of rats fed a HFD, and the results were interpreted as showing a link to the propensity of obesity susceptibility.

To date, some proteomic studies of liver proteins in response to a HFD have been reported, focusing on the inflammation and cellular stress-related pathways ${ }^{(26)}$, the lipogenic pathway ${ }^{(25)}$ and non-alcoholic fatty liver disease ${ }^{(23)}$. Differential hepatic protein profiling in response to a HFD in mice has been established by Sanchez et al. ${ }^{(37)}$ who found that two proteins (glutathione $S$-transferase $Y_{C}$ and peroxiredoxin 1) were down-regulated and three proteins (glutathione synthatase, Se-binding protein 1 and glucose-regulated protein 75) were up-regulated upon HFD feeding in the liver of C57BL/6 mice. They drew a conclusion that HFD feeding led to an increase in the hepatic supply of NEFA, resulting in an increased production of mitochondrial reactive oxygen species and consequent up-regulation of proteins involved in the protection of oxidative stress. The down-regulation of some anti-oxidative proteins in the HFD-fed group from the present results (catalase) and those of Sanchez and colleagues (glutathione $S$-transferase $Y_{c}$ and peroxiredoxin 1) suggests that these proteins are probably not the determinants of obesity susceptibility.

Recently, Li et al. ${ }^{(13)}$ established integrated transcriptomic and metabolomic profiling of OP and OR rats fed a HFD. They drew a conclusion that OP rats may be involved in an increased activity of the sympathetic nervous system and the Krebs cycle, an increased production of ketone bodies and an adaptive regulatory process to store excess lipids in the liver through the reverse cholesterol transport process. Unfortunately, we failed to link the present proteomic results to their transcriptomic and metabolomic data due to a limited number of genes commonly showing differential expression between OP and OR rat liver, as described below.

The present proteomic study revealed that a total of twelve proteins were significantly expressed between $\mathrm{OP}$ and $\mathrm{OR}$ rats. Most of these proteins were previously unrecognised for differential expression in rodent liver in response to a HFD. Therefore, we considered these proteins as potential marker proteins for determination of phenotypes in the liver of OP and OR rats, which are discussed below in detail.

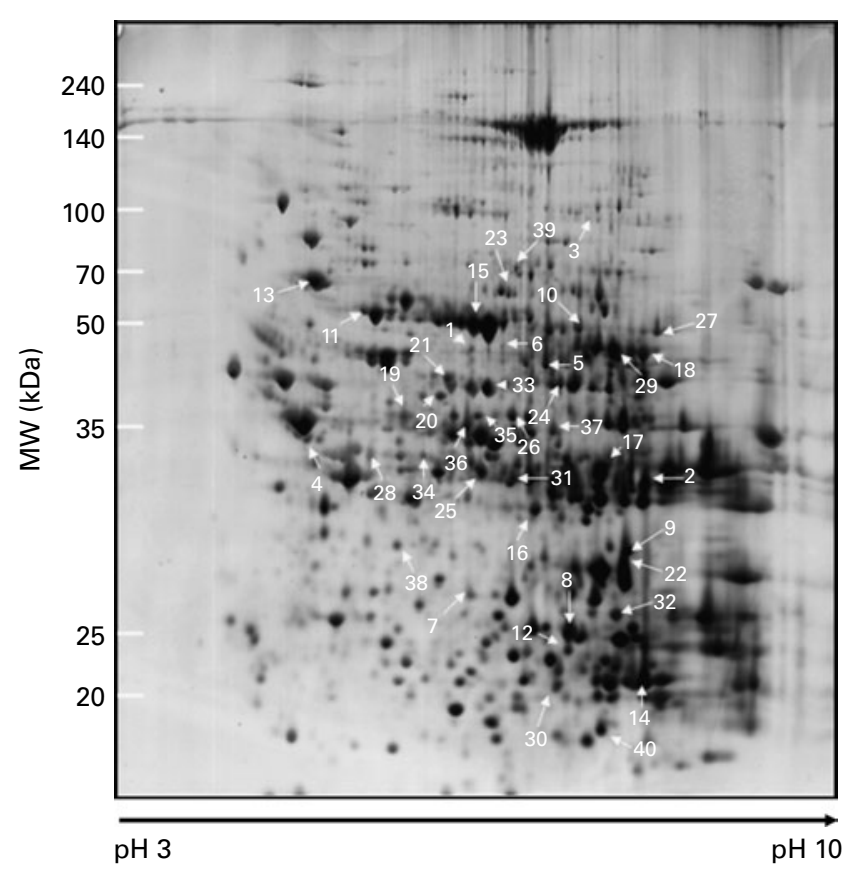

Fig. 2. Representative two-dimensional gel electrophoresis gel images of liver protein homogenate. Proteins were extracted and separated on IPG strips ( $\mathrm{pH} \mathrm{3-10)}$ for the first dimension, followed by $8 \%(\mathrm{w} / \mathrm{v})$ PAGE for the second dimension. Differentially expressed proteins are indicated by arrows. Protein numbers in gels are listed in Table 4. MW, molecular weight. 


\begin{tabular}{|c|c|c|c|c|c|c|c|c|c|c|c|c|c|}
\hline \multirow[b]{3}{*}{ Protein } & \multirow{3}{*}{$\begin{array}{l}\text { Accession } \\
\text { numbers }\end{array}$} & \multirow{3}{*}{$\begin{array}{l}\text { Nominal } \\
\text { mass }(\mathrm{Mr}) \ddagger\end{array}$} & \multirow{3}{*}{$\begin{array}{l}\text { Calculated } \\
\text { p/ }\end{array}$} & \multirow{3}{*}{$\begin{array}{l}\text { Sequence } \\
\text { coverage (\%) }\end{array}$} & \multirow[b]{3}{*}{ Peptides§ } & \multirow[b]{3}{*}{ Score\|l } & \multicolumn{6}{|c|}{ Protein volume density (\%) } & \multirow{3}{*}{$\begin{array}{l}\text { No. ir } \\
\text { gelף }\end{array}$} \\
\hline & & & & & & & \multicolumn{2}{|c|}{ Normal } & \multicolumn{2}{|c|}{ OP } & \multicolumn{2}{|c|}{ OR } & \\
\hline & & & & & & & Mean & SEM & Mean & SEM & Mean & SEM & \\
\hline Esterase 22 precursor & gi:13928768 & 61961 & 5.63 & 27 & $11 / 29$ & 98 & $0 \cdot 16^{\star *}$ & 0.02 & $0.05^{\star}$ & 0.02 & 0.15 & 0.03 & 1 \\
\hline Argininosuccinate synthetase 1 & gi:25453414 & 46752 & $7 \cdot 63$ & 47 & $16 / 32$ & 182 & $0.49^{\star \star}$ & 0.05 & $0 \cdot 27^{\star \star}$ & 0.05 & 0.46 & 0.03 & 2 \\
\hline Glycogen phosphorylase & gi:11560087 & 97877 & 6.75 & 32 & $29 / 34$ & 309 & $0 \cdot 04^{\star *}$ & 0.01 & $0.08^{\star \star}$ & 0.01 & 0.04 & 0.01 & 3 \\
\hline$\alpha 1$-Antitrypsin precursor & gi:203063 & 45978 & 5.7 & 30 & $10 / 18$ & 128 & $0 \cdot 11^{\star \star}$ & 0.01 & $0.04^{\star \star}$ & 0.01 & 0.11 & 0.01 & 4 \\
\hline Carboxylesterase 3 & gi:57013350 & 62393 & $6 \cdot 1$ & 25 & $11 / 20$ & 122 & $0 \cdot 18^{\star *}$ & 0.03 & $0 \cdot 36^{\star \star}$ & 0.03 & 0.2 & 0.02 & 5 \\
\hline Epoxide hydrolase 2, cytoplasmic & gi:149030321 & 58513 & 5.9 & 31 & $14 / 31$ & 125 & $0 \cdot 10^{\star \star}$ & 0.01 & $0.03^{\star \star}$ & 0.01 & 0.09 & 0.01 & 6 \\
\hline Malate dehydrogenase, cytoplasmic & gi:15100179 & 36631 & $6 \cdot 16$ & 29 & $7 / 18$ & 73 & $0 \cdot 11^{* *}$ & 0.01 & $0.06^{\star \star}$ & 0.01 & 0.1 & 0.01 & 7 \\
\hline Aryl sulfotransferase & gi:55765 & 33422 & $6 \cdot 41$ & 57 & $17 / 23$ & 251 & $0.58^{\star \star}$ & 0.03 & $0 \cdot 84^{\star \star}$ & 0.07 & 0.49 & 0.06 & 8 \\
\hline \multicolumn{14}{|l|}{ Ornithine carbamoyltransferase } \\
\hline BCS1 protein & gi:197245828 & 66000 & 7.57 & 37 & $15 / 30$ & 157 & $0.1^{\star \star}$ & 0.02 & $0.21^{\star \star}$ & 0.01 & 0.11 & 0.01 & 10 \\
\hline $\begin{array}{l}\text { Heat shock cognate } 71 \mathrm{kDa} \text { protein } \\
\text { Esterase D/formylglutathione }\end{array}$ & gi:13242237 & 71055 & $5 \cdot 37$ & 39 & $25 / 32$ & 252 & $0 \cdot 13^{\star \star}$ & 0.02 & $0 \cdot 24^{\star \star}$ & 0.02 & 0.17 & 0.02 & 11 \\
\hline hydrolase & gi:157823267 & 31971 & 6.44 & 57 & $13 / 19$ & 183 & $0 \cdot 17^{\star \star}$ & 0.02 & $0.23^{\star \star}$ & 0.02 & 0.15 & 0.02 & 12 \\
\hline Heat shock protein 5 precursor & gi:25742763 & 72473 & 5.07 & 29 & $18 / 25$ & 188 & $1 \cdot 14^{*}$ & 0.23 & 1.69 & 0.24 & $2 \cdot 14^{\star \star}$ & 0.29 & 13 \\
\hline \multicolumn{14}{|l|}{$\begin{array}{l}\text { Chain A, crystal structure of } \\
\text { S-glutathiolated carbonic }\end{array}$} \\
\hline $\begin{array}{l}\text { Serum albumin } \\
\text { Isovaleryl coenzyme A }\end{array}$ & gi: 124028612 & 70682 & $\begin{array}{l}6 \cdot 74 \\
6 \cdot 09\end{array}$ & $\begin{array}{l}68 \\
39\end{array}$ & $\begin{array}{l}15 / 22 \\
23 / 28\end{array}$ & $\begin{array}{l}240 \\
286\end{array}$ & $\begin{array}{l}1 \cdot 15 \\
1 \cdot 78^{\star \star}\end{array}$ & $\begin{array}{l}0.19 \\
0.17\end{array}$ & $\begin{array}{l}1 \cdot 14^{\star \star} \\
0.94^{\star}\end{array}$ & $\begin{array}{l}0.08 \\
0.03\end{array}$ & $\begin{array}{l}0.54^{\star \star} \\
1.03^{\star \star}\end{array}$ & $\begin{array}{l}0.13 \\
0.13\end{array}$ & $\begin{array}{l}14 \\
15\end{array}$ \\
\hline \multicolumn{14}{|l|}{ Isocitrate dehydrogenase 1} \\
\hline$(\mathrm{NADP}+)$, soluble & gi:13928690 & 47047 & 6.53 & 46 & $16 / 39$ & 150 & $0.68^{\star *}$ & 0.03 & 0.35 & 0.04 & $0.36^{* *}$ & 0.06 & 17 \\
\hline Catalase & gi:6978607 & 60062 & 7.07 & 43 & $16 / 18$ & 240 & $0.53^{\star \star}$ & 0.02 & $0.2325^{\star \star}$ & 0.0330 & $0.32^{\star \star}$ & 0.03 & 18 \\
\hline Glycerol kinase & gi:3122139 & 58238 & 5.49 & 38 & $20 / 40$ & 205 & $0 \cdot 12^{\star \star}$ & 0.02 & $0 \cdot 2770^{\star}$ & 0.0167 & $0 \cdot 24^{\star \star}$ & 0.01 & 19 \\
\hline Glycerate kinase & gi:157821525 & 55495 & 5.84 & 31 & $15 / 23$ & 174 & $0.25^{\star *}$ & 0.02 & 0.12 & 0.01 & $0 \cdot 11^{\star *}$ & 0.01 & 20 \\
\hline Sulfite oxidase & gi:294639 & 54606 & 5.79 & 30 & $12 / 24$ & 117 & $0.48^{\star *}$ & 0.05 & 0.24 & 0.02 & $0.23^{\star \star}$ & 0.03 & 21 \\
\hline $\begin{array}{l}\text { Pre-ornithine carbamoyl transferase } \\
\text { TNF receptor-associated protein } 1\end{array}$ & gi:205892 & 39988 & $9 \cdot 12$ & 47 & $15 / 24$ & 183 & $0.47^{\star \star}$ & 0.06 & 0.22 & 0.02 & $0 \cdot 22^{\star *}$ & 0.06 & 22 \\
\hline \multicolumn{14}{|l|}{ Aldehyde dehydrogenase family 7} \\
\hline member A1 & gi:149064287 & 56022 & $6 \cdot 25$ & 37 & $17 / 22$ & 233 & $0 \cdot 13^{\star \star}$ & 0.02 & 0.22 & 0.02 & $0.2^{* *}$ & 0.01 & 24 \\
\hline Adenosine kinase & gi: 149031258 & 38752 & $5 \cdot 82$ & 47 & $16 / 35$ & 174 & $0.32^{\star \star}$ & 0.05 & 0.53 & 0.02 & $0.48^{\star *}$ & 0.05 & 25 \\
\hline Se-binding protein 2 & gi: 149030730 & 51004 & 5.94 & 55 & $23 / 31$ & 280 & $0.3233^{\star \star}$ & 0.0224 & 0.1946 & 0.0228 & $0 \cdot 22^{\star \star}$ & 0.03 & 26 \\
\hline Transketolase & \multicolumn{12}{|c|}{ Eukaryotic translation initiation } & 27 \\
\hline $\begin{array}{l}\text { Eukaryotic translation initiation } \\
\text { factor } 4 \mathrm{~A} 1\end{array}$ & gi:149053067 & 44807 & $5 \cdot 61$ & 45 & $19 / 33$ & 168 & $0.0836^{\star \star}$ & 0.0197 & $0.1807^{\star}$ & 0.0168 & $0 \cdot 14^{\star \star}$ & 0.02 & 28 \\
\hline $\begin{array}{l}\text { Delta-1-pyrroline-5-carboxylate } \\
\text { dehydrogenase, mitochondrial }\end{array}$ & gi:197927423 & 62245 & $8 \cdot 26$ & 44 & $20 / 38$ & 216 & $0.7865^{\star}$ & 0.0676 & $0.6563^{\star \star}$ & 0.0734 & $0.42^{\star \star}$ & 0.03 & 29 \\
\hline $\begin{array}{l}\text { Chain } A \text {, crystal structure analysis } \\
\text { of rat enoyl-CoA hydratase in } \\
\text { complex with hexadienoyl-CoA }\end{array}$ & & & & & & & & & & & & & \\
\hline S-Adenosylhomocysteine hydrolase & gi: 149030911 & $\begin{array}{l}28498 \\
44800\end{array}$ & $\begin{array}{l}6.41 \\
6.08\end{array}$ & $\begin{array}{l}41 \\
35\end{array}$ & $\begin{array}{l}12 / 29 \\
16 / 24\end{array}$ & 177 & $\begin{array}{l}0.1647 \\
0.0575^{\star \star}\end{array}$ & $\begin{array}{l}0.0062 \\
0.0126\end{array}$ & $\begin{array}{l}0.1849^{\star n} \\
0.1332\end{array}$ & $\begin{array}{l}0.0161 \\
0.0063\end{array}$ & $0.14^{\star \star}$ & 0.01 & $\begin{array}{l}30 \\
31\end{array}$ \\
\hline $\begin{array}{l}\text { Aldo-keto reductase family } 1 \text {, } \\
\text { member } \mathrm{C} 14\end{array}$ & gi:19924087 & 37517 & $6 \cdot 67$ & 57 & $17 / 21$ & 243 & $0.3564^{\star \star}$ & 0.0285 & $0.2577^{\star \star}$ & 0.0231 & $0.14^{\star \star}$ & 0.03 & 32 \\
\hline
\end{tabular}




\begin{tabular}{|c|c|c|c|c|c|c|c|c|c|c|c|c|c|}
\hline \multirow[b]{3}{*}{ Protein } & \multirow[b]{3}{*}{$\begin{array}{l}\text { Accession } \\
\text { numbers }\end{array}$} & \multirow[b]{3}{*}{$\begin{array}{c}\text { Nominal } \\
\text { mass }(\mathrm{Mr}) \ddagger\end{array}$} & \multirow[b]{3}{*}{$\begin{array}{c}\text { Calculated } \\
\mathrm{p} /\end{array}$} & \multirow[b]{3}{*}{$\begin{array}{c}\text { Sequence } \\
\text { coverage (\%) }\end{array}$} & \multirow[b]{3}{*}{ Peptides§ } & \multirow[b]{3}{*}{ Score\|l } & \multicolumn{6}{|c|}{ Protein volume density (\%) } & \multirow[b]{3}{*}{$\begin{array}{l}\text { No. in } \\
\text { gel }\end{array}$} \\
\hline & & & & & & & \multicolumn{2}{|c|}{ Normal } & \multicolumn{2}{|c|}{ OP } & \multicolumn{2}{|c|}{ OR } & \\
\hline & & & & & & & Mean & SEM & Mean & SEM & Mean & SEM & \\
\hline \multicolumn{14}{|l|}{ Protein disulfide isomerase- } \\
\hline Phenylalanine hydroxylase & gi: 158262033 & 52301 & $5 \cdot 76$ & 49 & $14 / 18$ & 203 & $0.05^{\star *}$ & 0.004 & $0.09^{\star}$ & 0.01 & $0.07^{\star}$ & 0.01 & 34 \\
\hline $\begin{array}{l}\text { Dihydrolipoyllysine-residue } \\
\text { succinyltransferase component } \\
\text { of 2-oxoglutarate dehydrogenase }\end{array}$ & & & & & & & & & & & & & \\
\hline $\begin{array}{l}\text { complex, mitochondrial } \\
\text { Chain A, methionine adenosyl } \\
\text { transferase complexed with both }\end{array}$ & gi:62512126 & 49236 & 8.89 & 26 & $14 / 23$ & 151 & $0.13^{\star \star}$ & 0.01 & $0 \cdot 17^{\star \star}$ & 0.02 & $0 \cdot 09^{\star \star}$ & 0.01 & 35 \\
\hline substrates ATP and methionine & gi:157879476 & 41620 & $6 \cdot 35$ & 35 & $12 / 16$ & 176 & $0.21^{\star \star}$ & 0.02 & $0.28^{\star *}$ & 0.03 & $0.4^{\star \star}$ & 0.03 & 36 \\
\hline RCG34423 & gi:149052845 & 38308 & $6 \cdot 67$ & 21 & $7 / 20$ & 71 & 0.1425 & 0.0203 & $0 \cdot 1596^{\star}$ & 0.0229 & $0.2513^{\star *}$ & 0.0435 & 37 \\
\hline$\alpha-1$-Macroglobulin & gi:81872093 & 168388 & $6 \cdot 46$ & 4 & $6 / 6$ & 66 & $0.1370^{\star}$ & 0.0248 & 0.0791 & 0.0317 & 0.1857 & 0.0922 & 38 \\
\hline rCG43751 & gi: 149069236 & 83215 & $6 \cdot 58$ & 22 & $12 / 21$ & 105 & $0.0754^{\star \star}$ & 0.0075 & 0.0572 & 0.0039 & 0.0606 & 0.0133 & 39 \\
\hline rCG25753 & gi:149019103 & 26876 & 6.02 & 33 & 9/16 & 118 & $0.4882^{\star *}$ & 0.0351 & 0.2842 & 0.0351 & $0.2255^{\star}$ & 0.1685 & 40 \\
\hline
\end{tabular}

$\mathrm{Mr}$, relative molecular mass; BCS1, butyryl coenzyme A synthetase 1

Mean values were significantly different for normal, OP and OR rats: ${ }^{*} P<0.05,{ }^{* *} P<0.01$

$\dagger$ Accession numbers are the NCBInr database accession numbers.

¥ The nominal mass is the integer mass of the most abundant naturally occurring stable isotope of an element. The nominal mass of a molecule is the sum of the nominal masses of the elements in their empirical formula.

$\S$ Peptides are the number of $\mathrm{m} / \mathrm{z}$ values matched from an in silico digest $v$. the number of $\mathrm{m} / \mathrm{z}$ values unmatched.

II MASCOT probability-based molecular-weight search score calculated for peptide mass fingerprinting. Protein score is $-10 \times \log (P)$, where $P$ is the probability that the observed match is a random event; it is based on the NCBInr database using the MASCOT searching program as MS/MS data and protein scores $>61$ are significant $(P<0.05)$.

I No. in gel refers to numbers in two-dimensional gel electrophoresis image of Fig. 2. 

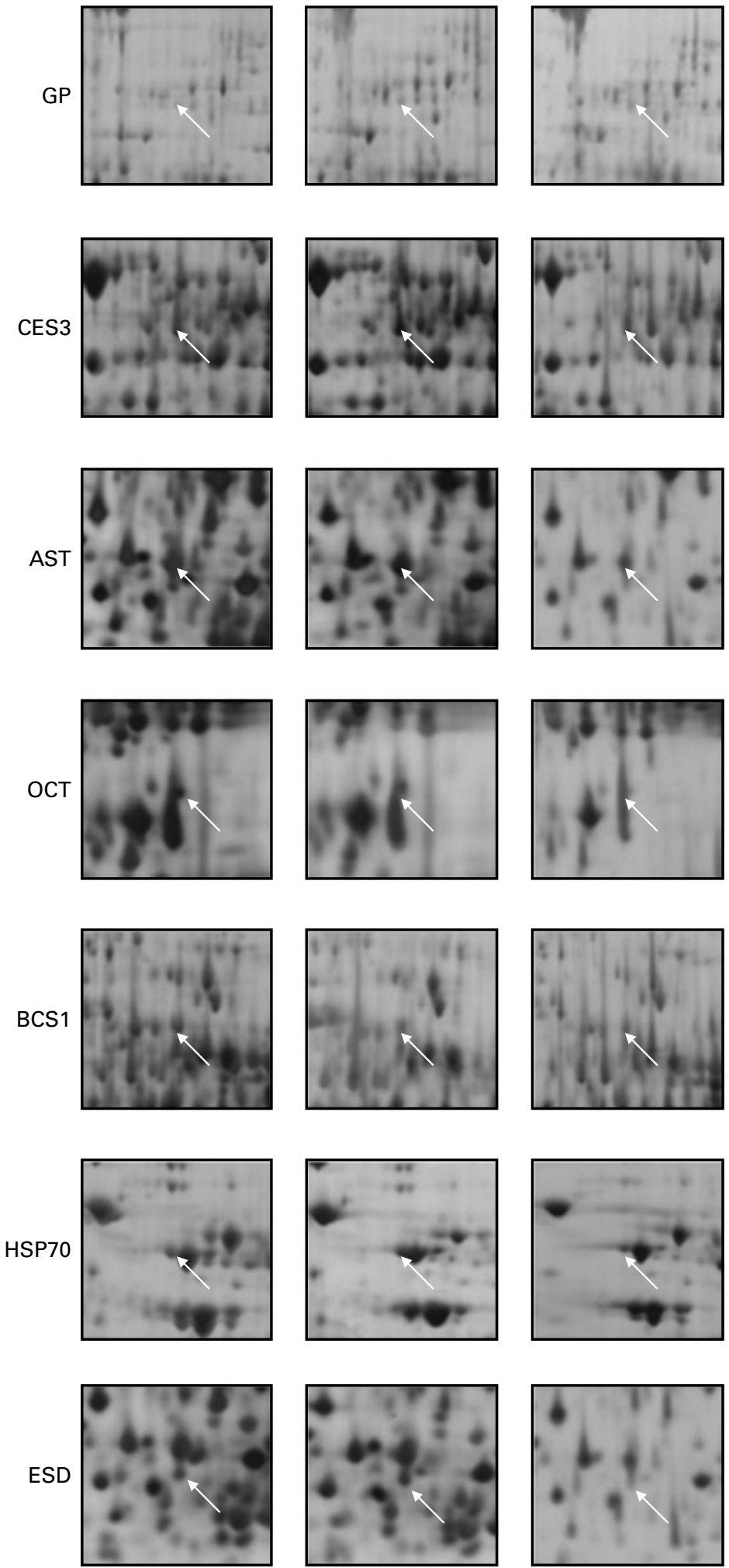

Normal

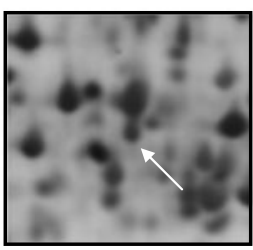

OP

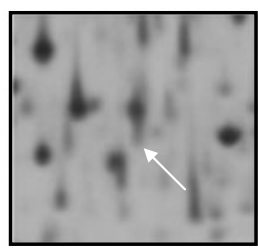

OR
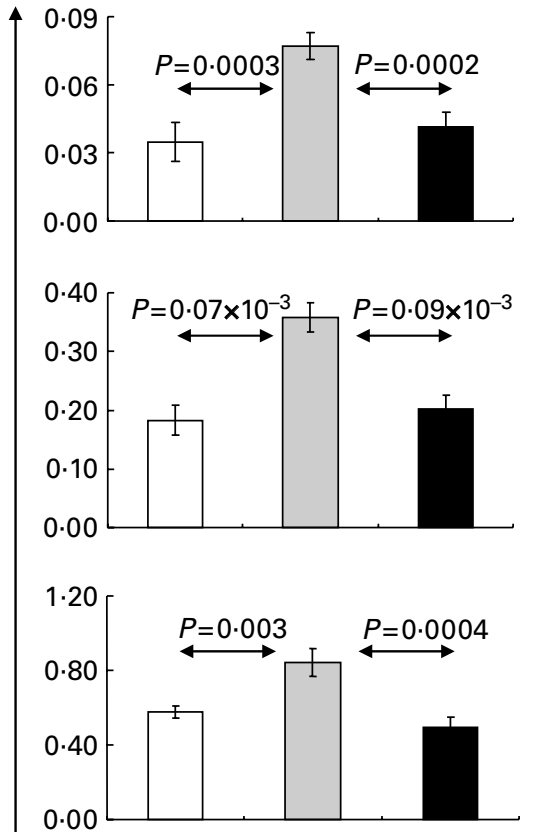

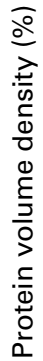
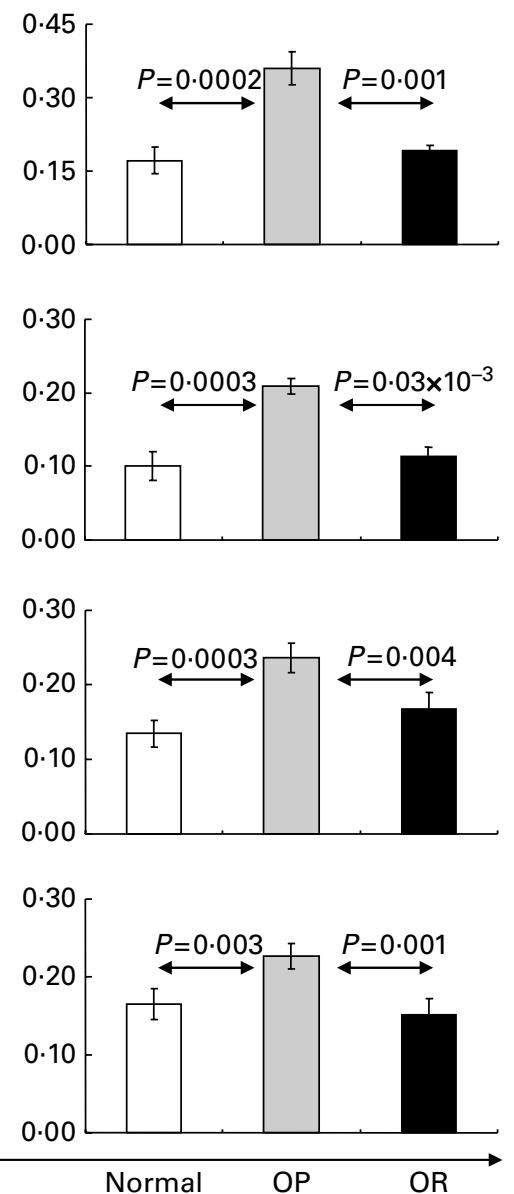

Fig. 3. Significantly increased liver proteins in obesity-prone (OP) rats compared with control and obesity-resistant (OR) rats. Zoom-in-gel images of each protein are shown with their average expression levels in three rats in each group. Values are means of volume density (\%) of target spot in each group, with their standard errors represented by vertical bars. Mean values were significantly different for the expression level between each group, indicated by $P$ values (ANOVA test). GP, glycogen phosphorylase; CES3, carboxylesterase 3; AST, aryl sulfotransferase; OCT, ornithine carbamoyltransferase; BCS1, butyryl coenzyme A synthetase 1; HSP70, heat shock proteins 70; ESD, esterase D. 

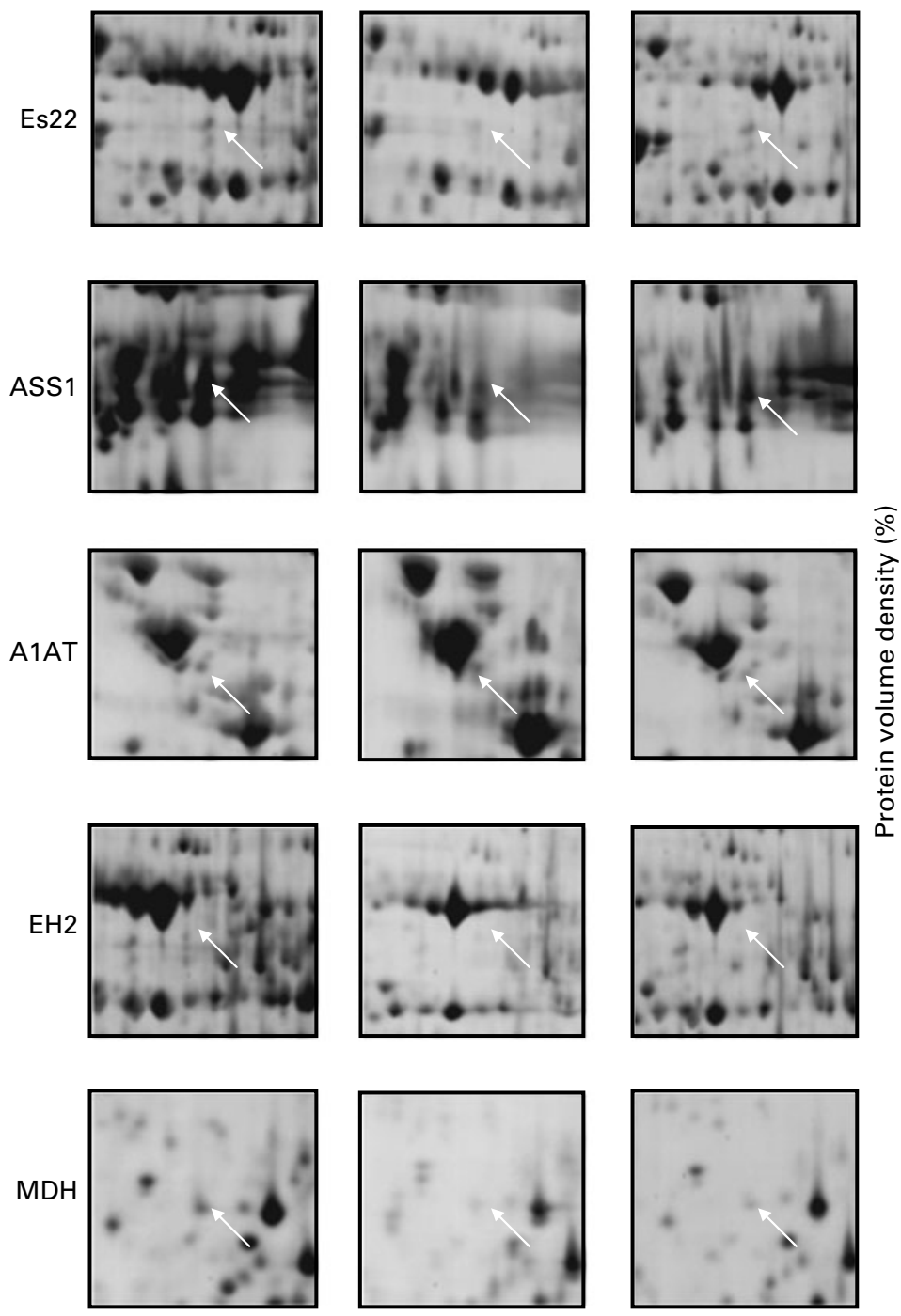

Normal
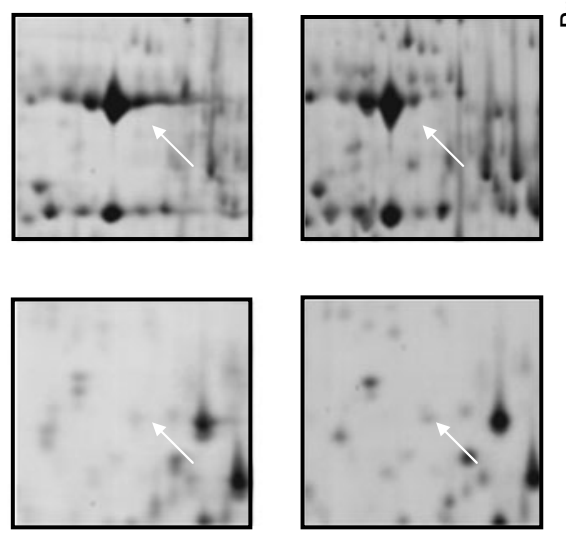

OP

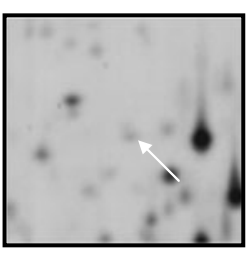

OR
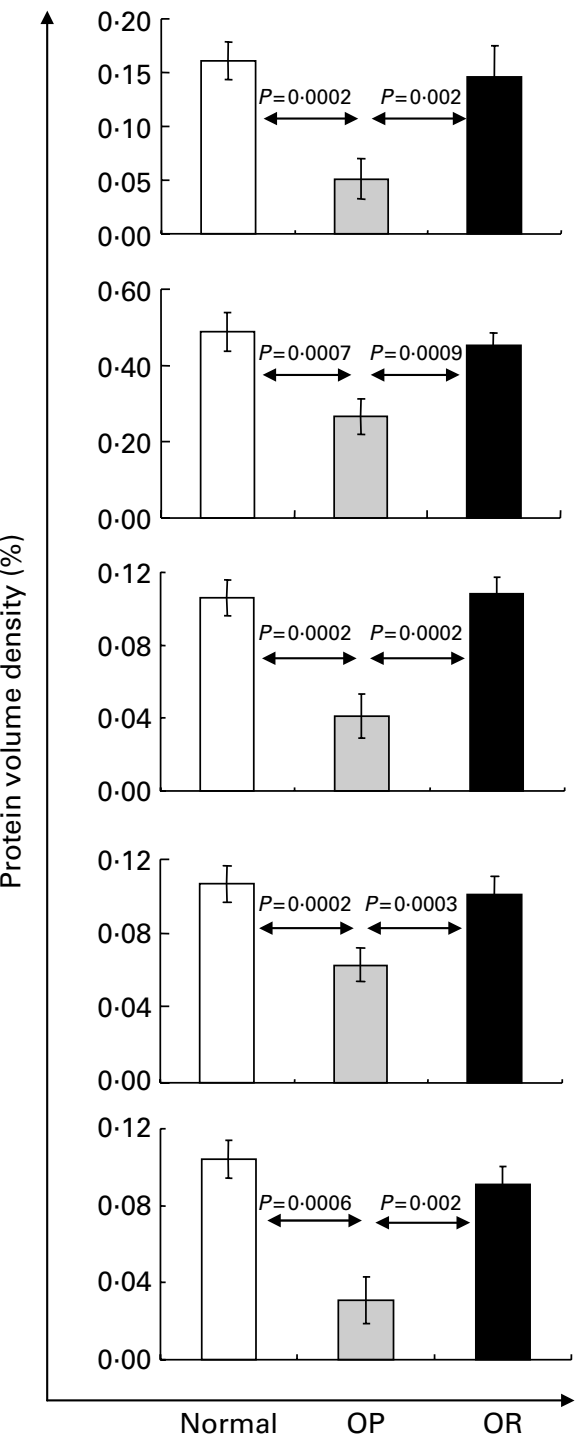

Fig. 4. Significantly decreased liver proteins in obesity-prone (OP) rats compared with control and obesity-resistant (OR) rats. Zoom-in-gel images of each protein are shown with their average expression levels in three rats in each group. Values are means of volume density (\%) of target spot in each group, with their standard errors represented by vertical bars. Mean values were significantly different for the expression level between each group, indicated by $P$ values (ANOVA test). Es22, esterase 22; ASS1, argininosuccinate synthetase 1; A1AT, $\alpha 1$-anti-trypsin; EH2, epoxide hydrolases 2; MDH, malate dehydrogenase.

Proteins up-regulated in obesity-prone and downregulated in obesity-resistant rat liver upon high-fat diet feeding

A total of seven proteins found in the liver tissue and identified for the first time in the present study showed up-regulation in $\mathrm{OP}$ rats while being maintained at low levels in normal and OR rats. Of particular interest in the present study was the up-regulation of GP, a key glycogenolytic enzyme, upon HFD feeding. In the diabetic liver, glucose production is increased, in part due to elevated glycogenolysis as a consequence of the enhanced activity of $\mathrm{GP}^{(38,39)}$. In addition, hepatic GP activity was higher in obese Zucker rats than in lean animals, which suggested that enhanced glycogenolysis resulting from elevated GP levels might be a consequence of hepatic insulin resistance or of the dysregulation of an insulin counter-regulatory hormone ${ }^{(40)}$. Moreover, increased GP activity has been reported to be a major contributing factor to impaired glycogen synthesis in hepatocytes from Zucker fatty fa/fa rats and could contribute to the lipogenic state ${ }^{(41)}$. The present findings from proteomic analysis are in line with these results showing that protein levels of GP in OP rats were also increased, suggesting that reduced levels of GP in OR rats would play a suppressive role in obesity development mediated by attenuation of insulin resistance.

Increased accumulation of fat in $\mathrm{OP}$ rats would subsequently promote expression of CES3, which converts a carboxylic ester to an alcohol and a carboxylate, and has recently been suggested to play a role in lipolysis ${ }^{(42)}$. Jernas et $a l .{ }^{(43)}$ recently demonstrated that expression of the CES1 gene is highly regulated in human adipose tissue, with increased levels in obese subjects and decreased levels during weight loss. CES3 has been recognised as having a major 

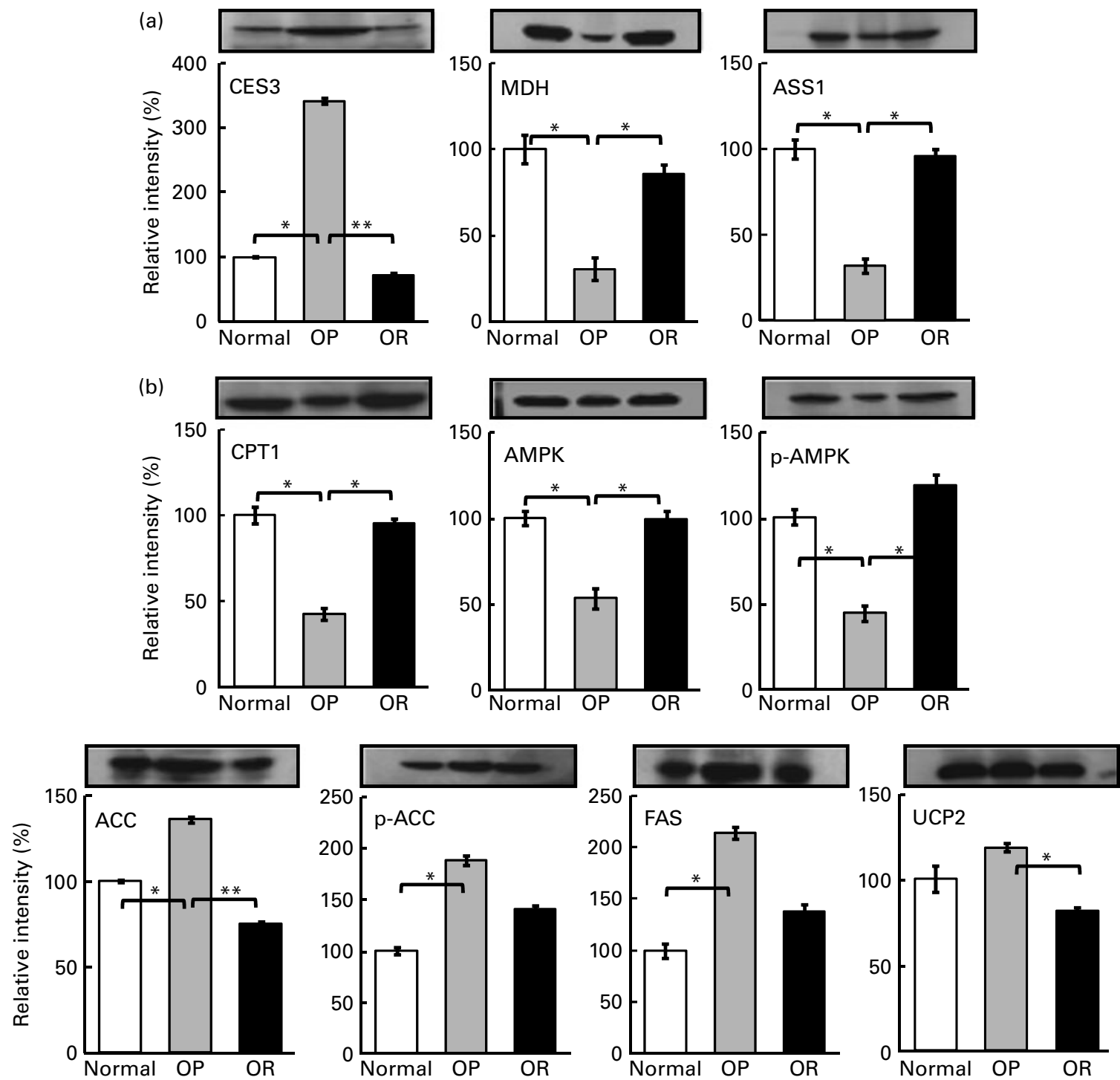

Fig. 5. Validation of (a) proteomic data for some proteins of interest and (b) differential expression patterns of seven metabolic liver proteins in normal, obesity-prone (OP) and obesity-resistant (OR) rats by immunoblot analysis. Band density was calculated by ImageMaster $2 \mathrm{D}$ software version 4.95 , and relative intensity $(\%)$ demonstrated that values of target proteins were normalised to those of $\beta$-actin. Mean values were significantly different: ${ }^{\star} P<0.05$, ${ }^{\star \star} P<0.01$. CES3, carboxylesterase $3 ; \mathrm{MDH}$, malate dehydrogenase; ASS1, argininosuccinate synthetase 1; CPT1, carnitine palmitoyltransferase 1; AMPK, adenosine monophosphate-activated protein kinase; p-AMPK, phosphorylated-AMPK; ACC, acetyl-CoA carboxylase; p-ACC, phosphorylated-ACC; FAS, fatty acid synthase; UCP2, uncoupling protein 2.

role in non-hormone-sensitive lipase activity in adipocytes and mediates some or all hormone-sensitive lipase-independent lipolysis in adipocytes ${ }^{(44)}$. However, the correlation between CES3 expression and lipolysis in the liver of rodents or human subjects has not yet been reported. The present proteomic analysis of liver also pointed out for the first time that OR rats showed lower CES3 expression than OP rats. There appears to be no requirement for an increase in the level of CES3 in OR rats, indicating lower fat accumulation in these rats.

A significant up- and down-regulation of AST was observed in OP and OR rats, respectively. AST from rat liver is known to catalyse the reactions for the formation of sulphate esters, which is a major metabolic pathway for substrates bearing hydroxyl functional groups and serves as a means for the preparation of lipophilic xenobiotics for excretion ${ }^{(45)}$.
A previous report has demonstrated that decreased AST expression is associated with resistance to rat hepatocarcinogenesis $^{(46)}$. However, the metabolic function of AST in relation to obesity has not yet been addressed. The present proteomic analysis found for the first time that protein levels of AST were higher in OP rats and showed a progressive increase with weight gain while showing a decrease in both normal and OR rats. This led us to hypothesise that AST might be a plausible marker protein for indication of susceptibility to obesity.

We also found for the first time that increased levels of the OCT precursor are supposed to reflect the increased risk for obesity because significantly higher levels were detected in the liver of OP rats. OCT is one of the key enzymes in the urea cycle that catalyses the reaction between carbamoyl phosphate and ornithine to form citrulline and phosphate in 
the mitochondria of mammalian tissues ${ }^{(47)}$. Considering the function of this enzyme, no explanation for the difference in OCT precursor expression between OP and OR rats can be found in the present proteomic study. The present result is in line with the finding of Yamini et al. ${ }^{(48)}$, showing that OCT levels were significantly affected by phenotype (obese greater than lean) of rats fed a diet containing high levels of carbohydrates $^{(48)}$. It has been postulated that high levels of OCT in the liver of OP rats might originate from accumulation of a higher concentration of $\mathrm{NH}_{3}$ in obese subjects.

Another interesting result from the present proteomic study is the appearance of high levels of BCS1 in OP rats. BCS1 belongs to the family of ligases whose other names in common use are acyl-CoA synthetase medium-chain family member 1 (ACSM1) and butyrate-CoA ligase. BCS1 was thought to function as an acyl-CoA synthetase, which is involved in the fatty acid metabolism ${ }^{(49)}$. Overexpression of acyl-CoA synthetase induces lipid deposition in hepatic cells and in the liver of rodents in vivo ${ }^{(50)}$, and is an indicator of hypertension in rats $^{(49)}$. In the present study, increased levels of BCS1 in the liver of OP rats probably resulted from high fat accumulation in obese subjects with a hypertensive state, suggesting that ACSM1 can be used as a marker protein for prediction of obesity risk.

Increased expression of some HSP in obese rodent models or human subjects has been reported in many earlier studies $^{(51,52)}$. HSP are a class of functionally related proteins whose expression is increased when cells are exposed to elevated temperatures or other stress. Among them, HSP70 is a constitutively expressed chaperone that is also inducible by heat shock stress. It binds to nascent polypeptides to facilitate correct folding and also participates in the formation and repair of higher-order protein structures ${ }^{(53,54)}$. HSP70 has been used as a molecular target for diagnosis and treatment of several diseases ${ }^{(55)}$. In the present study, levels of HSP70 were higher in OP rats, whereas reduced levels were found in normal and OR rats. Previously, we also found a significant increase in HSP27 in HFD-induced obese rat skeletal muscle ${ }^{(56)}$. The present study for the first time provides a link of this protein to risk of obesity, particularly to strong predictors of susceptibility to obesity.

Of particular interest to us in the present study was the upregulation of ESD upon HFD feeding. ESD is a member of the non-specific esterase family, whose members are defined by their reaction with synthetic $O$-acyl ester substrates ${ }^{(57)}$. Findings showing that the highest levels of this enzyme were found in liver compared with other tissues implied that ESD might play a role in the detoxification process ${ }^{(57)}$. Due to its polymorphic nature, ESD has been used as a genetic marker for the diagnosis of hereditary retinoblastoma ${ }^{(57)}$. To date, no evidence has linked its expression to obesity development. In the present study, OP rats showed higher ESD expression than normal and OR rats, implying their potential role in obesity. However, the physiological significance of this change remains to be determined.
Proteins down-regulated in obesity-prone and up-regulated in obesity-resistant rat liver upon high-fat diet feeding

Analysis of liver samples resulted in the identification of five proteins that were down-regulated upon HFD feeding in OP rats but up-regulated in normal and OR rats. Most of these proteins were previously not recognised for differential expression in the liver in response to a HFD. In the present study, the level of difference in two esterases (ESD and Es22) failed to show any consistent pattern between OP and OR rats in response to HFD feeding. We detected downregulation of the Es22 precursor in OP rats but not in OR rats. However, as mentioned earlier, the expression pattern of ESD was the opposite. Since Es22 is an enzyme that hydrolyses retinyl ester-stored excess dietary vitamin A after esterification with fatty acids, overexpression of Es22 attenuates the formation of cellular retinyl ester stores. In hepatocytes, retinyl esters are hydrolysed, and unesterified retinol is associated with retinol-binding protein 4 for secretion, which is one of the key players in insulin resistance ${ }^{(58)}$. Consistent with this, abnormal expression of this enzyme may be closely linked to causes of metabolic diseases such as diabetes and obesity. The present proteomic analysis revealed that protein levels of the Es22 precursor were decreased in the liver of $\mathrm{OP}$ rats compared with those in OR and normal rats, suggesting the possibility that this protein caused reduced adiposity and resistance to obesity development in OR rats.

ASS1 is a main rate-limiting enzyme in the urea cycle and plays a role in $\mathrm{NH}_{3}$ detoxification, which occurs in the liver ${ }^{(59)}$. In the present study, the results of the downregulation of ASS1 argue strongly against the result of the up-regulation of another urea cycle enzyme OCT in obese rats ${ }^{(60)}$. This opposite regulation mode implies that the urea cycle is not an influencing factor in determining obesity susceptibility despite the significantly differential expression between $\mathrm{OP}$ and $\mathrm{OR}$ rats. To the best of our knowledge, there is no report to correlate ASS expression with obesity or other metabolic syndromes.

A significant down-regulation of the A1AT precursor in OP rats upon HFD feeding is an important outcome of the present study. A1AT is a serine protease inhibitor that is synthesised in and secreted from the liver ${ }^{(61)}$, and has been reported to play important roles in immunoregulation, antiinflammatory response and liver function ${ }^{(62,63)}$. For example, A1AT deficiency is associated with liver diseases such as cirrhosis. A1AT is favoured over restitution as the protease released by leucocytes during the inflammatory response to hepatocytic necrosis; therefore, it may play a role in the prevention of cirrhosis ${ }^{(61)}$. The present proteomic analysis revealed down-regulation of the A1AT precursor in the liver of $\mathrm{OP}$ rats. This is the first finding to suggest the possibility that maintenance of high levels of A1AT in the liver of rodents may cause resistance to obesity.

We also found that down-regulation of $\mathrm{EH} 2$ and $\mathrm{MDH}$ indicates a higher risk for obesity development. EH2 belongs to the family of $\mathrm{EH}$ whose main functions include detoxification, catabolism and regulation of signalling molecules ${ }^{(64)}$. 
Although detoxifying activity is one of the main functions of $\mathrm{EH}$, interestingly, yet paradoxically, inhibition of $\mathrm{EH}$ has been reported to be a potential therapeutic treatment for several diseases ${ }^{(65)}$. As signalling lipids, lipid-derived epoxides have diverse functions in the regulatory processes, such as cell proliferation, control of blood pressure and inflammatory processes. Therefore, abnormal regulation of $\mathrm{EH}$ can cause dysfunction of the liver.

$\mathrm{MDH}$ catalyses the oxidation of cytoplasmic malate to oxaloacetate and thereby produces reducing equivalents ${ }^{(66)}$. The cytoplasmic form of $\mathrm{MDH}$ is involved in de novo fat synthesis by providing extra mitochondrial-reducing equivalents from the oxidation of malate. Its activity has been reported to be significantly lower in adipose tissue of obese mice compared with their lean littermates ${ }^{(37,67)}$. Taken together, the suppressive role of these two proteins under HFD conditions suggests their potential as biomarkers for risk of obesity.

Difference in lipogenic and $\beta$-oxidation enzymes between obesity-prone and obesity-resistant rats

It is recognised that feeding the HFD to rats increases uptake of lipids in the liver and increases hepatic synthesis of NEFA, as well as decreases NEFA $\beta$-oxidation in the liver ${ }^{(68)}$. In the present study, down-regulation of AMPK and CPT1 as well as up-regulation of ACC and FAS in the liver of OP rats is the key result. We focused on the difference in the expression of AMPK, which plays an important role in the regulation of energy homeostasis. A recent study has indicated that AMPK is a key modulator of lipid metabolism ${ }^{(69)}$. The pathway that is central to the integrated effects of AMPK in liver tissues in the reduction of obesity risk and insulin resistance is the stimulation of fatty acid oxidation ${ }^{(70)}$. In the liver, AMPK phosphorylates ACC, activates malonyl-CoA decarboxylase and suppresses the gene expression of lipogenic enzymes, such as ACC1 and FAS ${ }^{(71)}$. Activation of AMPK stimulates hepatic lipid oxidation mainly through a reduction in malonyl-CoA and thereby inhibits CPT1, a rate-limiting step for the entry of long-chain fatty acyl-CoA into the mitochondria for $\beta$-oxidation $^{(69,70,72)}$. In the present study, we observed a reduction in the protein content of activated AMPK in the liver of OP rats fed a HFD, which thereby resulted in decreased $\beta$-oxidation of fatty acids (Fig. 5)

Collectively, susceptibility to obesity development in rats under HFD may, at least in part, result from differences in the regulation of key lipogenic and $\beta$-oxidation enzymes. In this regard, we hypothesised that $\mathrm{OP}$ rats undergo slow fat oxidation, thereby leading to excessive accumulation of dietary fat in liver tissues, compared with OR rats. To test this hypothesis, we next examined the expression patterns of UCP2 between the OP and OR groups by Western blot analysis. Although UCP2 activity has been recognised as an intracellular regulator of oxidative stress and thermogenesis, its exact role remains controversial ${ }^{(73,74)}$. UCP2 is identified as a fatty acid-responsive mitochondrial inner membrane carrier protein showing a wide tissue distribution with a substantially increased presence in fatty liver ${ }^{(73)}$. The role of UCP2 in energy dissipation differs among tissues, and the contribution of UCP2 to uncoupling of oxidative phosphorylation in hepatocytes is limited ${ }^{(74)}$. UCP2 as a negative regulator of reactive oxygen species production has successfully been tested in a variety of experimental settings. The absence of UCP2 was associated with increased oxidative stress $^{(74-77)}$. In the present study, in line with earlier findings, higher UCP2 expression was observed in the liver of rats fed a HFD (OP rats). However, interestingly, OR rats showed the lowest UCP2 expression among the three groups, suggesting an alleviated state of oxidative stress. Taken together, it can be suggested that UCP2 in hepatocytes did not contribute to the prevention of HFD-induced obesity.

\section{Acknowledgements}

The present study was supported by the Midcareer Researcher Programme (grant no. R01-2008-000-10277-0) and SRC programme (Center for Food and Nutritional Genomics: grant no. 2010-0001888) of the National Research Foundation of Korea funded by the Ministry of Education, Science and Technology. The authors declare that they have no conflict of interest. X. W. and J.-W. C. carried out the proteomic analysis and data analyses and interpretation. J. I. J., D. H. K., T. S. O. and D. K. C. established the obesity animal model. J. W. Y. is the project leader who was responsible for the planning of the present study and for writing the manuscript.

\section{References}

1. Friedman JM (2009) Obesity: causes and control of excess body fat. Nature 459, 340-342.

2. Chang S, Graham B, Yakubu F, et al. (1990) Metabolic differences between obesity-prone and obesity-resistant rats. Am J Physiol 259, R1103-R1110.

3. Levin BE, Hogan S \& Sullivan AC (1989) Initiation and perpetuation of obesity and obesity resistance in rats. Am J Physiol 256, R766-R771.

4. Levin BE \& Sullivan AC (1987) Glucose, insulin and sympathoadrenal activation. J Auton Nerv Syst 20, 233-242.

5. Flanagan AM, Brown JL, Santiago CA, et al. (2008) High-fat diets promote insulin resistance through cytokine gene expression in growing female rats. J Nutr Biochem 19, 505-513.

6. Ramis JM, Bibiloni B, Moreiro J, et al. (2005) Tissue leptin and plasma insulin are associated with lipoprotein lipase activity in severely obese patients. J Nutr Biochem 16, $279-285$.

7. Levin BE (1991) Glucose increases rat plasma norepinephrine levels by direct action on the brain. Am J Physiol 261, R1351-R1357.

8. Levin BE, Triscari J \& Sullivan AC (1983) Altered sympathetic activity during development of diet-induced obesity in rat. Am J Physiol 244, R347-R355.

9. Alexander J, Chang GQ, Dourmashkin JT, et al. (2006) Distinct phenotypes of obesity-prone AKR/J, DBA2J and C57BL/6J mice compared to control strains. Int $J$ Obes (Lond) 30, 50-59.

10. Abou Mrad J, Yakubu F, Lin D, et al. (1992) Skeletal muscle composition in dietary obesity-susceptible and dietary obesity-resistant rats. Am J Physiol 262, R684-R688.

11. Eberhart GP, West DB, Boozer CN, et al. (1994) Insulin sensitivity of adipocytes from inbred mouse strains resistant 
or sensitive to diet-induced obesity. Am J Physiol 266, R1423-R1428.

12. Levin BE, Finnegan MB, Marquet E, et al. (1984) Defective brown adipose oxygen consumption in obese Zucker rats. Am J Physiol 247, E94-E100.

13. Li H, Xie Z, Lin J, et al. (2008) Transcriptomic and metabonomic profiling of obesity-prone and obesity-resistant rats under high fat diet. J Proteome Res 7, 4775-4783.

14. Ji H \& Friedman MI (2008) Reduced hepatocyte fatty acid oxidation in outbred rats prescreened for susceptibility to diet-induced obesity. Int J Obes (Lond) 32, 1331-1334.

15. Jackman MR, Kramer RE, MacLean PS, et al. (2006) Trafficking of dietary fat in obesity-prone and obesity-resistant rats. Am J Physiol Endocrinol Metab 291, E1083-E1091.

16. Hu CC, Qing K \& Chen Y (2004) Diet-induced changes in stearoyl-CoA desaturase 1 expression in obesity-prone and -resistant mice. Obes Res 12, 1264-1270.

17. Gazzana G \& Borlak J (2009) An update on the mouse liver proteome. Proteome Sci 7, 35.

18. Chinese Human Liver Proteome Profiling Consortium (2010) First insight into human liver proteome from PROTEOME(SKY)-LIVER(Hu) 1.0, a publicly available database. J Proteome Res 9, 79-94.

19. Thome-Kromer B, Bonk I, Klatt M, et al. (2003) Toward the identification of liver toxicity markers: a proteome study in human cell culture and rats. Proteomics 3, 1835-1862.

20. Gazzana G \& Borlak J (2007) Improved method for proteome mapping of the liver by 2-DE MALDI-TOF MS. J Proteome Res 6, 3143-3151.

21. Shi R, Kumar C, Zougman A, et al. (2007) Analysis of the mouse liver proteome using advanced mass spectrometry. J Proteome Res 6, 2963-2972.

22. Song Y, Hao Y, Sun A, et al. (2006) Sample preparation project for the subcellular proteome of mouse liver. Proteomics 6, 5269-5277.

23. Zhang X, Yang J, Guo Y, et al. (2010) Functional proteomic analysis of nonalcoholic fatty liver disease in rat models: enoyl-coenzyme a hydratase down-regulation exacerbates hepatic steatosis. Hepatology 51, 1190-1199.

24. Eccleston HB, Andringa KK, Betancourt AM, et al. (2011) Chronic exposure to a high fat diet induces hepatic steatosis, impairs nitric oxide bioavailability, and modifies the mitochondrial proteome in mice. Antioxid Redox Signal (epublication ahead of print version 31 March 2011).

25. Jiang L, Wang Q, Yu Y, et al. (2009) Leptin contributes to the adaptive responses of mice to high-fat diet intake through suppressing the lipogenic pathway. PLoS One 4, e6884.

26. de Roos B, Rungapamestry V, Ross K, et al. (2009) Attenuation of inflammation and cellular stress-related pathways maintains insulin sensitivity in obese type I interleukin-1 receptor knockout mice on a high-fat diet. Proteomics 9 , 3244-3256.

27. Folch J, Lees M \& Sloane Stanley GH (1957) A simple method for the isolation and purification of total lipides from animal tissues. J Biol Chem 226, 497-509.

28. Nepokroeff CM, Lakshmanan MR \& Porter JW (1975) Fattyacid synthase from rat liver. Methods Enzymol 35, 37-44.

29. Ochoa S (1995) Malic enzyme: mallic enzymes from pigeon and wheat germ. In Methods in Enzymmology, pp. 323-326 [SP Colowick and NO Kaplan, editors]. New York: Academic Press.

30. Lazarow PB (1981) Assay of peroxisomal beta-oxidation of fatty acids. Methods Enzymol 72, 315-319.

31. Markwell MA, McGroarty EJ, Bieber LL, et al. (1973) The subcellular distribution of carnitine acyltransferases in mammalian liver and kidney. A new peroxisomal enzyme. J Biol Chem 248, 3426-3432.
32. Bradford MM (1976) A rapid and sensitive method for the quantitation of microgram quantities of protein utilizing the principle of protein-dye binding. Anal Biochem 72, 248-254.

33. Kim SW, Hwang HJ, Baek YM, et al. (2008) Proteomic and transcriptomic analysis for streptozotocin-induced diabetic rat pancreas in response to fungal polysaccharide treatments. Proteomics 8, 2344-2361.

34. Kumar SG, Rahman MA, Lee SH, et al. (2009) Plasma proteome analysis for anti-obesity and anti-diabetic potentials of chitosan oligosaccharides in ob/ob mice. Proteomics $\mathbf{9}$, 2149-2162.

35. Shevchenko A, Tomas H, Havlis J, et al. (2006) In-gel digestion for mass spectrometric characterization of proteins and proteomes. Nat Protoc 1, 2856-2860.

36. Fernandez J, Gharahdaghi F \& Mische SM (1998) Routine identification of proteins from sodium dodecyl sulfate-polyacrylamide gel electrophoresis (SDS-PAGE) gels or polyvinyl difluoride membranes using matrix assisted laser desorption/ ionization-time of flight-mass spectrometry (MALDI-TOF-MS). Electrophoresis 19, 1036-1045.

37. Sanchez JC, Converset V, Nolan A, et al. (2003) Effect of rosiglitazone on the differential expression of obesity and insulin resistance associated proteins in lep/lep mice. Proteomics 3, 1500-1520.

38. Moller DE (2001) New drug targets for type 2 diabetes and the metabolic syndrome. Nature 414, 821-827.

39. Zibrova D, Grempler R, Streicher R, et al. (2008) Inhibition of the interaction between protein phosphatase 1 glycogentargeting subunit and glycogen phosphorylase increases glycogen synthesis in primary rat hepatocytes. Biochem $J$ 412, 359-366.

40. Alemzadeh R, Holshouser S, Massey P, et al. (2002) Chronic suppression of insulin by diazoxide alters the activities of key enzymes regulating hepatic gluconeogenesis in Zucker rats. Eur J Endocrinol 146, 871-879.

41. Aiston S, Peak M \& Agius L (2000) Impaired glycogen synthesis in hepatocytes from Zucker fatty fa/fa rats: the role of increased phosphorylase activity. Diabetologia $\mathbf{4 3}$, 589-597.

42. Lehner R \& Verger R (1997) Purification and characterization of a porcine liver microsomal triacylglycerol hydrolase. Biochemistry 36, 1861-1868.

43. Jernas M, Olsson B, Arner P, et al. (2009) Regulation of carboxylesterase 1 (CES1) in human adipose tissue. Biochem Biophys Res Commun 383, 63-67.

44. Soni KG, Lehner R, Metalnikov P, et al. (2004) Carboxylesterase 3 (EC 3.1.1.1) is a major adipocyte lipase. J Biol Chem 279, 40683-40689.

45. Duffel MW \& Jakoby WB (1981) On the mechanism of aryl sulfotransferase. J Biol Chem 256, 11123-11127.

46. Ringer DP, Norton TR \& Howell BA (1990) 2-Acetylaminofluorene-mediated alteration in the level of liver arylsulfotransferase IV during rat hepatocarcinogenesis. Cancer Res 50, 5301-5307.

47. Wraith JE (2001) Ornithine carbamoyltransferase deficiency. Arch Dis Child 84, 84-88.

48. Yamini S, Staples RC, Hansen CT, et al. (1991) Effect of dietary carbohydrate on liver and kidney enzyme activities and plasma amino acids in the $\mathrm{LA} / \mathrm{N}-\mathrm{cp}$ rat. Int $J$ Obes $\mathbf{1 5}$ 189-203.

49. Haketa A, Soma M, Nakayama T, et al. (2004) Two mediumchain acyl-coenzyme A synthetase genes, SAH and MACS1, are associated with plasma high-density lipoprotein cholesterol levels, but they are not associated with essential hypertension. J Hypertens 22, 1903-1907. 
50. Li LO, Mashek DG, An J, et al. (2006) Overexpression of rat long chain acyl-coa synthetase 1 alters fatty acid metabolism in rat primary hepatocytes. J Biol Chem 281, 37246-37255.

51. Schlesinger MJ (1990) Heat shock proteins. J Biol Chem 265 12111-12114

52. Kim S, Sohn I, Ahn JI, et al. (2004) Hepatic gene expression profiles in a long-term high-fat diet-induced obesity mouse model. Gene 340, 99-109.

53. Tsukahara F, Yoshioka T \& Muraki T (2000) Molecular and functional characterization of HSC54, a novel variant of human heat-shock cognate protein 70. Mol Pharmacol 58, 1257-1263.

54. Egerton M, Moritz RL, Druker B, et al. (1996) Identification of the $70 \mathrm{kD}$ heat shock cognate protein (Hsc70) and alphaactinin-1 as novel phosphotyrosine-containing proteins in T lymphocytes. Biochem Biophys Res Commun 224, 666-674.

55. Gaston JS (2002) Heat shock proteins and innate immunity. Clin Exp Immunol 127, 1-3.

56. Kim DH, Joo JI, Choi JW, et al. (2010) Differential expression of skeletal muscle proteins in high-fat diet-fed rats in response to capsaicin feeding. Proteomics 10, 2870-2881.

57. Lee WH, Wheatley W, Benedict WF, et al. (1986) Purification, biochemical characterization, and biological function of human esterase D. Proc Natl Acad Sci U S A 83, 6790-6794.

58. Schreiber R, Taschler U, Wolinski H, et al. (2009) Esterase 22 and beta-glucuronidase hydrolyze retinoids in mouse liver J Lipid Res 50, 2514-2523.

59. Husson A, Brasse-Lagnel C, Fairand A, et al. (2003) Argininosuccinate synthetase from the urea cycle to the citrulline-NO cycle. Eur J Biochem 270, 1887-1899.

60. Engel K, Hohne W \& Haberle J (2009) Mutations and polymorphisms in the human argininosuccinate synthetase (ASS1) gene. Hum Mutat 30, 300-307.

61. McLean C, Greene CM \& McElvaney NG (2009) Gene targeted therapeutics for liver disease in alpha-1 antitrypsin deficiency. Biologics 3, 63-75.

62. Kaushal S, Annamali M, Blomenkamp K, et al. (2010) Rapamycin reduces intrahepatic alpha-1-antitrypsin mutant $\mathrm{Z}$ protein polymers and liver injury in a mouse model. Exp Biol Med (Maywood) 235, 700-709.

63. Nemeth A (1994) Pathogenesis of liver disease in alpha 1-antitrypsin deficiency. Acta Paediatr Suppl 393, 5-7.

64. Decker M, Arand M \& Cronin A (2009) Mammalian epoxide hydrolases in xenobiotic metabolism and signalling. Arch Toxicol 83, 297-318
65. Morisseau C \& Hammock BD (2005) Epoxide hydrolases: mechanisms, inhibitor designs, and biological roles. Annu Rev Pharmacol Toxicol 45, 311-333.

66. Schmid GM, Converset V, Walter N, et al. (2004) Effect of high-fat diet on the expression of proteins in muscle, adipose tissues, and liver of $\mathrm{C} 57 \mathrm{BL} / 6$ mice. Proteomics $\mathbf{4}$, 2270-2282.

67. Hastings IM \& Hill WG (1990) Analysis of lines of mice selected for fat content. 2. Correlated responses in the activities of enzymes involved in lipogenesis. Genet Res $\mathbf{5 5}$, $55-61$.

68. Lavoie JM \& Gauthier MS (2006) Regulation of fat metabolism in the liver: link to non-alcoholic hepatic steatosis and impact of physical exercise. Cell Mol Life Sci $\mathbf{6 3}$, $1393-1409$.

69. Lage R, Dieguez C, Vidal-Puig A, et al. (2008) AMPK: a metabolic gauge regulating whole-body energy homeostasis. Trends Mol Med 14, 539-549.

70. Kahn BB, Alquier T, Carling D, et al. (2005) AMP-activated protein kinase: ancient energy gauge provides clues to modern understanding of metabolism. Cell Metab 1, 15-25.

71. Woods A, Azzout-Marniche D, Foretz M, et al. (2000) Characterization of the role of AMP-activated protein kinase in the regulation of glucose-activated gene expression using constitutively active and dominant negative forms of the kinase. Mol Cell Biol 20, 6704-6711.

72. Nguyen P, Leray V, Diez M, et al. (2008) Liver lipid metabolism. J Anim Physiol Anim Nutr (Berl) 92, 272-283.

73. Baffy $\mathrm{G}$ (2005) Uncoupling protein-2 and non-alcoholic fatty liver disease. Front Biosci 10, 2082-2096.

74. Horimoto M, Fulop P, Derdak Z, et al. (2004) Uncoupling protein-2 deficiency promotes oxidant stress and delays liver regeneration in mice. Hepatology 39, 386-392.

75. Negre-Salvayre A, Hirtz C, Carrera G, et al. (1997) A role for uncoupling protein-2 as a regulator of mitochondrial hydrogen peroxide generation. FASEB J 11, 809-815.

76. Arsenijevic D, Onuma H, Pecqueur C, et al. (2000) Disruption of the uncoupling protein-2 gene in mice reveals a role in immunity and reactive oxygen species production. Nat Genet 26, 435-439.

77. Petzke KJ, Riese C \& Klaus S (2007) Short-term, increasing dietary protein and fat moderately affect energy expenditure, substrate oxidation and uncoupling protein gene expression in rats. J Nutr Biochem 18, 400-407. 